ISSN = 1980-993X - doi:10.4136/1980-993X
www.ambi-agua.net
E-mail: ambi-agua@agro.unitau.br
Tel.: (12) 3625-4212

\title{
Conservação e reúso de águas usando o método Diagrama de Fontes de Água para processos em batelada: estudo de casos
}

\author{
(http://dx.doi.org/10.4136/ambi-agua.565)
}

\author{
Reinaldo Coelho Mirre ${ }^{1}$; Shaula Christine Leal Ferreira ${ }^{2}$; \\ Aline Rodrigues Dias ${ }^{3}$; Fernando Luiz Pellegrini Pessoa ${ }^{4}$ \\ Universidade Federal do Rio de Janeiro, Escola de Química \\ ${ }^{1}$ e-mail: reinaldomirre@ hotmail.com; ${ }^{2}$ e-mail: shaula.leal@gmail.com; \\ ${ }^{3}$ e-mail: ninedias1@gmail.com; ${ }^{4}$ e-mail: pessoa@eq.ufrj.br
}

\section{RESUMO}

O gerenciamento de recursos hídricos tem sido um fator importante para a sustentabilidade dos processos industriais, visto que há uma necessidade crescente pelo desenvolvimento de metodologias voltadas para conservação e uso racional da água. $\mathrm{O}$ objetivo deste trabalho foi aplicar o método Diagrama de Fontes de Água (DFA), usado na definição de metas de mínimo consumo de água, a processos que operam em regime batelada. Foram gerados e avaliados cenários de reúso de correntes obtidos pela aplicação do método a partir de dados de quantidade de água e concentração de contaminantes nas operações. Foram apresentados dois estudos de caso com o objetivo de demonstrar a redução de consumo de água e da geração de efluentes, além de custos de tratamento final e de investimento em tanques de estocagem, em relação à configuração inicial. Os cenários mostraram-se bastante promissores, com reduções que alcançam $45 \%$, em termos de consumo hídrico e geração de efluentes, e $37 \%$, em termos de custos de tanques, sem a necessidade de processos de regeneração. Com isso, a técnica empregada mostrou-se relevante e flexível como alternativa às ferramentas sistemáticas voltadas para a minimização do consumo de água em processos industriais, exercendo importante papel em um programa de gerenciamento de recursos hídricos.

Palavras-chave: reúso de efluentes; tanque de estocagem; síntese de redes de transferência de massa.

\section{Water conservation and reuse using the Water Sources Diagram method for batch process: case studies}

\begin{abstract}
The water resources management has been an important factor for the sustainability of industrial processes, since there is a growing need for the development of methodologies aimed at the conservation and rational use of water. The objective of this work was to apply the heuristic-algorithmic method called Water Sources Diagram (WSD), which is used to define the target of minimum water consumption, to batch processes. Scenarios with reuse of streams were generated and evaluated with application of the method from the data of water quantity and concentration of contaminants in the operations. Two case studies aiming to show the reduction of water consumption and wastewater generation, and final treatment costs besides investment in storage tanks, were presented. The scenarios showed great promising, achieving reduction up to $45 \%$ in water consumption and wastewater generation, and a
\end{abstract}


MIRRE, R. C.; FERREIRA, S. C. L.; DIAS, A. R.; PESSOA, F. L. P. Conservação e reúso de águas usando o método Diagrama de Fontes de Água para processos em batelada: estudo de casos. Ambi-Agua, Taubaté, v.7, n. 1, p. 182-203, 2012. (http://dx.doi.org/10.4136/ambi-agua.565)

reduction of around $37 \%$ on cost of storage tanks, without the need to allocate regeneration processes. Thus, the WSD method showed to be a relevant and flexible alternative regarding to systemic tools aimed at minimizing the consumption of water in industrial processes, playing an important role within a program of water resources management.

Keywords: wastewater reuse; storage tank; mass exchange networks synthesis.

\section{INTRODUÇÃO}

Nas últimas décadas, os custos com tratamento de efluentes industriais vêm aumentando gradativamente. No meio industrial, a água é empregada para consumo humano, como matéria prima, como fluido auxiliar, na geração de energia, como fluido de aquecimento e/ou resfriamento, dentre outros. A quantidade e a qualidade da água necessárias ao desenvolvimento das atividades industriais dependem das características do setor, dados os diferentes níveis de qualidade e da capacidade de produção que podem ser empregados. A cobrança pelo uso da água irradia um cenário de aumento nos custos de produção, tornando-se importante adotar medidas para conservação e uso racional, adequação de tratamento e aplicação de técnicas de reúso.

No campo da Integração de Processos Químicos, uma das primeiras contribuições voltadas para minimizar a vazão total de efluentes aquosos surgiu com o trabalho de ElHalwagi e Manousiouthakis (1989), que introduziram o conceito de redes de transferência de massa. A ideia consiste na transferência de contaminantes das correntes ricas para um conjunto de correntes pobres, a partir da rede gerada, com um procedimento similar ao de uma rede de transferência de energia. Entretanto, a maior contribuição ocorreu com os trabalhos de Wang e Smith (1994a,b; 1995a,b), apresentando uma metodologia que possibilite minimizar as metas de consumo de água em sistemas com um e múltiplos contaminantes, fazendo uso dos conceitos básicos de curva composta e transferência vertical. A metodologia foi estendida para casos de regeneração, restrição de vazão, taxa de perda fixa e múltiplas fontes de água. Castro et al. (1999) desenvolveram uma metodologia para o alcance da meta do consumo mínimo de água de modo simultâneo à síntese da rede de transferência de massa, considerando situações de reúso e regeneração, para um contaminante.

Gomes et al. (2007) estenderam os trabalhos de Castro et al. (1999) e Wang e Smith (1994a,b) por meio do algoritmo Diagrama de Fontes de Água (DFA). Foram testadas várias situações a partir do exemplo de Wang e Smith (1994a) para um contaminante, em opções como máximo reúso, múltiplas fontes de água, perdas de vazão referentes ao processo, restrições de vazão, regeneração com reúso, e regeneração com reciclo. Constatou-se que o consumo mínimo de água primária foi alcançado para o caso de máximo reuso, mesmo com restrição de vazão. A necessidade de fontes externas de água pode ser reduzida com o uso de processos regenerativos; porém, neste caso, há um trade-off ("conflito de escolha") entre a redução do consumo de água da fonte externa e o processo de regeneração mais adequado.

Os processos industriais que operam em regime de batelada têm sido alvo de estudos voltados para a necessidade de se desenvolver metodologias que busquem minimizar os efluentes gerados. A grande maioria das metodologias encontradas na literatura destina-se aos processos contínuos, as quais empregam técnicas de programação matemática para a resolução de problemas (Alva-Argáez et al., 1998; Doyle e Smith, 1997). Tais técnicas facilitam a abordagem de correntes com múltiplos contaminantes, em função da maior complexidade envolvida. Uma outra parcela dos trabalhos disponíveis envolve o uso de métodos gráficos (Wang e Smith, 1995a,b; Majozi et al., 2006), cuja abordagem é mais propícia à análise para um contaminante. Considerando a sua potencialidade, as técnicas 
MIRRE, R. C.; FERREIRA, S. C. L.; DIAS, A. R.; PESSOA, F. L. P. Conservação e reúso de águas usando o método Diagrama de Fontes de Água para processos em batelada: estudo de casos. Ambi-Agua, Taubaté, v.7, n. 1, p. 182-203, 2012. (http://dx.doi.org/10.4136/ambi-agua.565)

matemáticas são superiores às técnicas gráficas, mesmo para processos em batelada, em que a dimensão do tempo é um fator relevante.

Wang e Smith (1995b) iniciaram o estudo sobre síntese de redes de transferência de massa em processos em batelada, apresentando um método gráfico em que o tempo é tratado como uma restrição primária, enquanto que a força motriz concentração como restrição secundária (Time Pinch Analysis).

Almató et al. (1997) estabeleceram uma metodologia baseada em regras heurísticas e otimização matemática para minimização do consumo de água limpa em processos em batelada, onde introduziram o conceito de tanques de estocagem, a fim de oportunizar maiores possibilidades de reúso. A função objetivo seleciona o tanque que atenderá a demanda de cada corrente, indicando aquele para o qual o efluente deve ser enviado. O método foi aplicado aos processos de uma fábrica de sucos, alcançando-se uma reutilização de até $37 \%$. Os tanques de estocagem atuam como estações de mistura e distribuição para outros pontos da planta, proporcionando um aumento nas oportunidades de reúso de água entre as operações que permitem a relaxação de restrições dependentes do tempo. Almató et al. (1999) e Puigjaner et al. (2000) desenvolveram um programa computacional de interface gráfica que permite reduzir o consumo de água em processos batelada, a partir do reúso de efluentes aquosos utilizando tanques de estocagem de água.

Jödicke et al. (2001) empregaram um modelo de programação linear, em que os custos totais, operacionais (água limpa, tratamento de efluentes, bombeamento) e de investimento (tubulação, tanques) foram minimizados em um dado período de tempo. A síntese de redes de transferência de massa para processos em batelada também foi gerada por Foo et al. (2004; 2005a), a partir de uma tabela de intervalo de composição dependente do tempo; também apresentaram um procedimento voltado para a síntese de redes considerando a presença de um tanque de estocagem para reúso (Foo et al., 2005b), sem, no entanto, realizar estimativas de custos para as redes estruturadas.

Majozi (2005) apresentou uma formulação matemática baseada numa superestrutura que engloba todas as possibilidades de reciclo e reúso em plantas batelada multipropósito, considerando casos de presença e ausência de um tanque central de estocagem; com isso, alcançaram economias superiores a 50\% com o uso do tanque. Majozi et al. (2006) apresentaram uma técnica gráfica que inclui a identificação de oportunidades de reúso e reciclo de água dentro do processo e entre processos. As redes consideraram a inclusão de vasos de processos voltados para estocagem de água.

Muitos dos trabalhos que envolvem a síntese de redes de reúso de águas em sistemas batelada são tratados a partir de problemas de otimização matemática. Méndez et al. (2006) realizaram uma revisão dos métodos de otimização empregados para programação da produção de processos em batelada. Além dos trabalhos já mencionados, têm-se recentes contribuições, dentre os quais: Chang e Li (2006), que estudaram a equalização ótima de vazão de efluentes e concentração de contaminantes em plantas batelada; Shoaib et al. (2008) e Oliver et al. (2008), que combinaram programação matemática com análise Pinch para sintetizar redes de água em processos em batelada; Gouws et al. (2008), que estenderam o modelo de Majozi (2005) para minimização de água em plantas multipropósito utilizando tanque central de estocagem; Rabie e El-Hawagi (2008), que minimizaram o custo anual total a partir de um procedimento hierárquico para a síntese e planejamento de redes de reciclo de água em processos em batelada.

Tokos e Pintarič (2009) apresentaram uma aplicação industrial para a otimização de uma rede de água, em uma cervejaria. Vários modelos matemáticos foram desenvolvidos a fim de reduzir o uso de água limpa. Os modelos foram baseados no projeto desenvolvido por Kim e Smith (2004). Como resultado, os custos com tratamento de água sofreram redução de $27 \%$. Chen et al. (2009) também utilizaram programação matemática para a síntese de redes com o 
MIRRE, R. C.; FERREIRA, S. C. L.; DIAS, A. R.; PESSOA, F. L. P. Conservação e reúso de águas usando o método Diagrama de Fontes de Água para processos em batelada: estudo de casos. Ambi-Agua, Taubaté, v.7, n. 1, p. 182-203, 2012. (http://dx.doi.org/10.4136/ambi-agua.565)

uso de tanque central de estocagem. Majozi e Gouws (2009a,b) utilizaram programação não linear para redução da captação de água e da geração de efluentes em processos em batelada com múltiplos contaminantes, aplicável a situações sem o uso de tanque central. Vale ainda destacar as contribuições de Zhou et al. (2009) e Gouws e Majozi (2009).

Immich et al. (2007) apresentaram uma adaptação do método DFA para um processo em batelada. O procedimento foi comparado à técnica gráfica empregada por Majozi et al. (2006). Os resultados encontrados foram semelhantes aos da literatura, porém ficou evidente a simplicidade da aplicação do DFA na consideração de problemas deste tipo. Amim et al. (2007) também aplicaram o método DFA para um processo em batelada, cujos resultados foram praticamente similares aos da literatura.

Chen e Lee (2008) utilizaram um método gráfico para aplicá-lo a um processo batelada simples e batelada em ciclo, alcançando reduções de $40 \%$ e $60 \%$ nos custos do processo, respectivamente. Como a maioria dos métodos gráficos, o trabalho se restringe a um único contaminante.

O método DFA (Gomes et al., 2007) é um procedimento algorítmico-heurístico baseado em equações de balanço material e em regras heurísticas que procuram estabelecer conexões ótimas entre fontes e sumidouros de água, dentro do processo industrial. O procedimento divide o problema em intervalos de concentração, cujos limites são considerados como fontes internas de água, enquanto que a água primária e a água regenerada são definidas como fontes externas. As concentrações são ordenadas e representadas em um diagrama de concentrações. As regras heurísticas adotadas estabelecem que: i) as fontes externas são utilizadas somente na indisponibilidade de fontes internas; ii) é necessário que a maior quantidade de massa seja transferida dentro do intervalo de concentração; e iii) quando uma operação é dividida em vários intervalos, a prioridade de alocação provém da corrente da mesma operação. A metodologia gera fluxogramas de processos em diferentes situações de reúso e regeneração, incluindo reciclo. Possui ainda a vantagem da geração simultânea de fluxogramas alternativos para o processo.

Este trabalho teve como objetivo aplicar o método DFA, originalmente desenvolvido para processos contínuos, na síntese de fluxogramas hídricos em processos que operam sob o regime de batelada. Procurou-se gerar redes em cenários que visam o uso racional da água. A metodologia foi apresentada simultaneamente com o desenvolvimento de um problema da literatura, detalhando sua resolução utilizando-se o método. Com isso, dois estudos de caso foram apresentados, sendo avaliados cenários que incluem a necessidade de se empregar tanques de estocagem de água, os quais contribuem para as oportunidades de máximo reúso no processo.

\section{METODOLOGIA}

A abordagem de problemas em batelada envolve a disponibilidade de informações relativas à massa de cada contaminante presente, à quantidade de água requerida, ao tempo inicial e final de cada batelada para alcance do efeito desejado, à massa (estocagem) de água disponível para o reúso, e às concentrações máximas de entrada e saída das respectivas operações (Majozi, 2005). Em problemas dessa natureza, o emprego de tanques de estocagem representa fonte adicional para reúso, tornando-se um depósito para cada operação. Em configurações em que inexiste um tanque de estocagem, a água necessária para cada operação é suprida por correntes de entrada de água limpa, correntes de reúso e/ou reciclo, ou ainda uma combinação destas correntes.

O procedimento algorítmico-heurístico DFA desenvolvido para processos contínuos é apresentado passo a passo em Gomes et al. (2007), sendo cada restrição (vazão fixa, múltiplas fontes e perda de vazão) discutida separadamente. 
MIRRE, R. C.; FERREIRA, S. C. L.; DIAS, A. R.; PESSOA, F. L. P. Conservação e reúso de águas usando o método Diagrama de Fontes de Água para processos em batelada: estudo de casos. Ambi-Agua, Taubaté, v.7, n. 1, p. 182-203, 2012. (http://dx.doi.org/10.4136/ambi-agua.565)

O procedimento apresentado neste trabalho para processos em batelada segue a abordagem de Immich et al. (2007), e é ilustrado pela aplicação aos dados do estudo de caso tratado por Foo et al. (2005b), conforme mostrado na Tabela 1.

Tabela 1. Dados do processo em batelada (Foo et al., 2005b).

\begin{tabular}{|c|c|c|c|c|c|}
\hline $\begin{array}{c}\text { Demanda, } \\
\mathbf{D}_{\mathbf{j}}\end{array}$ & $\begin{array}{c}\text { Vazão limite } \\
(\mathrm{t} / \mathrm{h})\end{array}$ & $\begin{array}{c}\text { Concentração } \\
(\text { ppm })\end{array}$ & $\begin{array}{c}\text { Tempo } \\
\text { inicial }(h)\end{array}$ & $\begin{array}{c}\text { Tempo } \\
\text { final (h) }\end{array}$ & $\begin{array}{c}\text { Carga mássica } \\
\text { limite }(t)\end{array}$ \\
\hline D1 & 20 & 0 & 0 & 1,0 & 20 \\
\hline D2 & 100 & 50 & 1,0 & 3,5 & 250 \\
\hline D3 & 40 & 50 & 3,0 & 5,0 & 80 \\
\hline D4 & 10 & 400 & 1,0 & 3,0 & 20 \\
\hline Fonte, $S_{i}$ & $\begin{array}{l}\text { Vazão limite } \\
(\mathbf{t} / \mathbf{h})\end{array}$ & $\begin{array}{c}\text { Concentração } \\
(\text { ppm) }\end{array}$ & $\begin{array}{c}\text { Tempo } \\
\text { inicial (h) }\end{array}$ & $\begin{array}{c}\text { Tempo } \\
\text { final }(h)\end{array}$ & $\begin{array}{l}\text { Carga mássica } \\
\text { limite (t) }\end{array}$ \\
\hline $\mathrm{S} 1$ & 20 & 100 & 0 & 1,0 & 20 \\
\hline $\mathrm{S} 2$ & 100 & 100 & 1,0 & 3,5 & 250 \\
\hline $\mathrm{S} 3$ & 40 & 800 & 3,0 & 5,0 & 80 \\
\hline $\mathrm{S} 4$ & 10 & 800 & 1,0 & 3,0 & 20 \\
\hline
\end{tabular}

A estrutura do problema pode ser dividida em intervalos de tempo de batelada, em que cada qual apresentam as operações, em estados terminais ou intermediários. Para adaptação à abordagem do DFA, o problema original pode ser tratado como uma operação na qual se incorpora sua respectiva fonte e demanda, conforme os dados representados na Tabela 2.

Tabela 2. Nova representação do conjunto de dados do processo.

\begin{tabular}{c|ccccc}
\hline Operação & $\begin{array}{c}\text { Vazão } \\
\text { limite (t/h) }\end{array}$ & $\begin{array}{c}\text { Concentração } \\
(\mathbf{p p m})\end{array}$ & $\begin{array}{c}\text { Tempo } \\
\text { inicial (h) }\end{array}$ & $\begin{array}{c}\text { Tempo } \\
\text { final (h) }\end{array}$ & $\begin{array}{c}\text { Carga } \\
\text { mássica limite } \\
\text { (t) }\end{array}$ \\
\hline D1/S1 (OP1) & 20 & 0 & 0 & 1,0 & 20 \\
D2/S2 (OP2) & 100 & 50 & 1,0 & 3,5 & 250 \\
D3/S3 (OP3) & 40 & 50 & 3,0 & 5,0 & 80 \\
D4/S4 (OP4) & 10 & 400 & 1,0 & 3,0 & 20 \\
\hline
\end{tabular}

Para cada operação envolvida, tem-se a estrutura segmentada do intervalo de tempo de batelada, de acordo com a Figura 1.

A estrutura do reúso de correntes aquosas deve atender ao intervalo sequencial de tempo, em que o reúso só é permitido ao término das operações inseridas nos intervalos de tempo subsequentes. Neste caso, o conjunto dos intervalos de tempo de batelada para reúso sequencial é dado por $\{0-1,0 \mathrm{~h} ; 1,0-3,0 \mathrm{~h} ; 3,0-3,5 \mathrm{~h} ; 3,5-5,0 \mathrm{~h}\}$, de tal modo que o método DFA é aplicado em cada intervalo de tempo. Assim, no primeiro intervalo $(0-1,0 \mathrm{~h})$, a operação 1 se inicia e finaliza, tornando disponível a quantidade de 20 t para eventual reúso em período posterior. 
MIRRE, R. C.; FERREIRA, S. C. L.; DIAS, A. R.; PESSOA, F. L. P. Conservação e reúso de águas usando o método Diagrama de Fontes de Água para processos em batelada: estudo de casos. Ambi-Agua, Taubaté, v.7, n. 1, p. 182-203, 2012. (http://dx.doi.org/10.4136/ambi-agua.565)
Tempo $(\mathrm{h}) \Rightarrow \quad 0$
1,0
3,0
3,5
5,0

OP1
OP2
OP3
OP4

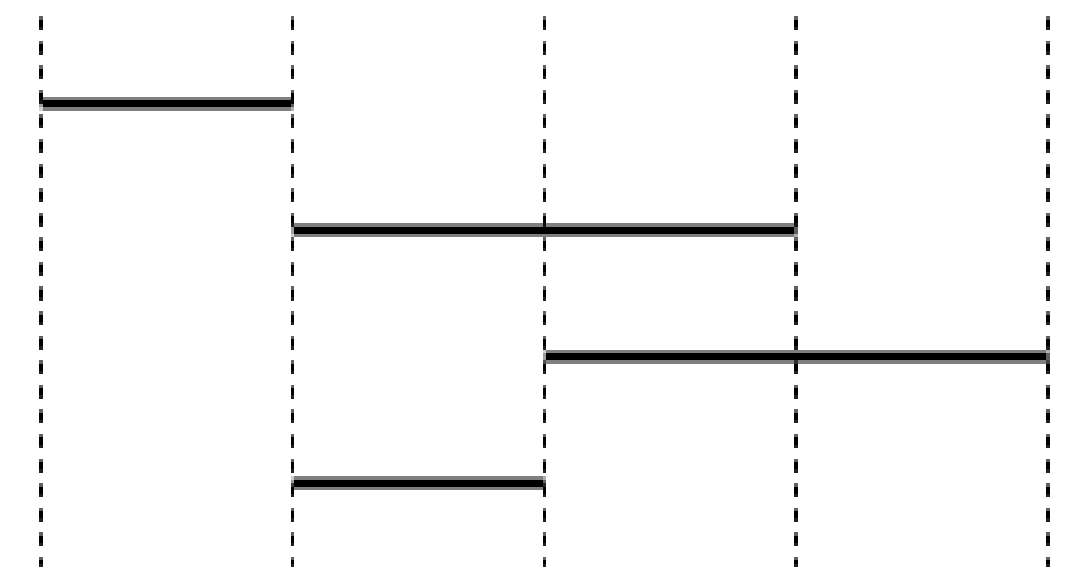

Figura 1. Representação das operações em cada intervalo de tempo da batelada.

No segundo intervalo $(1,0-3,0 \mathrm{~h})$, a quantidade de água necessária para suprir a necessidade da operação 2 pode ser proveniente da operação 1 , uma vez que, no período considerado, já encontra-se finalizada e disponível para reúso. Deve-se, portanto, calcular, por meio de um balanço no ponto de mistura, a quantidade necessária de água para minimizar a contribuição da água limpa $(0 \mathrm{ppm})$. O problema consiste em encontrar a vazão $\mathrm{F}$, ou melhor, a quantidade que ajuste o mínimo consumo de água limpa, maximizando o reúso da corrente efluente da operação 1 pela combinação das correntes a montante do misturador, conforme a Figura 2.

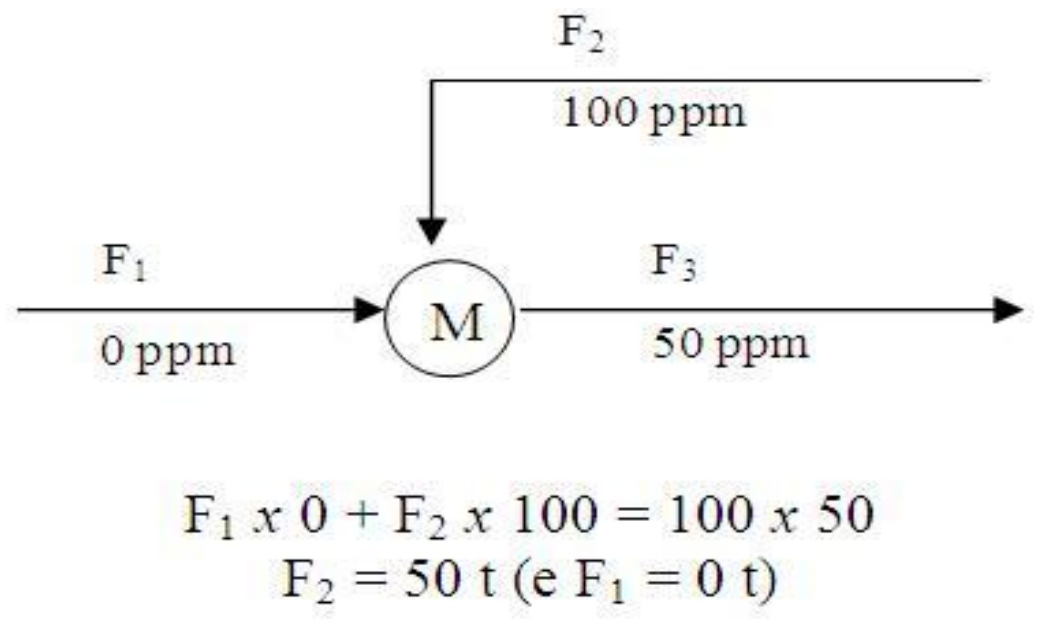

Figura 2. Balanço material para cálculo da menor quantidade de água $\left(\mathrm{F}_{3}\right)$ a jusante do misturador $\mathrm{M}$.

Como a quantidade calculada proveniente da operação 1 para o reúso de modo que minimize o emprego da água limpa corresponde a $50 \mathrm{t}$ e, somente encontram-se disponíveis $20 \mathrm{t}$, procura-se aproveitar essa máxima quantidade disponível para recalcular, a partir de $20 \mathrm{t}$ de $\mathrm{F}_{2}$, a contribuição de $\mathrm{F}_{1}$ (água limpa) para este caso, ou seja, quando há a máxima contribuição possível do reúso de da operação 1 . Neste caso, o valor encontrado para $F_{1}$ é de $20 \mathrm{t}$, totalizando $\mathrm{F}_{3}$ equivalente a $40 \mathrm{t}$. 
MIRRE, R. C.; FERREIRA, S. C. L.; DIAS, A. R.; PESSOA, F. L. P. Conservação e reúso de águas usando o método Diagrama de Fontes de Água para processos em batelada: estudo de casos. Ambi-Agua, Taubaté, v.7, n. 1, p. 182-203, 2012. (http://dx.doi.org/10.4136/ambi-agua.565)

Da mesma forma, o efluente da operação 2 pode ser prontamente reutilizado na operação 4, onde são necessárias 5,7 t para assimilar a carga desta operação dentro do intervalo de 100 ppm (de onde se busca o efluente para reúso) a 800 ppm.

No terceiro intervalo $(3,0-3,5 \mathrm{~h})$, a parcela remanescente da operação 2 , e que não foi reutilizada na operação 4, é então destinada em 20 t para a operação 3, entre 100 ppm e 400 ppm.

No quarto e último intervalo $(3,5-5,0 \mathrm{~h})$, encontra-se apenas a operação 3 , e a quantidade necessária para assimilação do contaminante já se torna suficiente.

Após a realização do DFA em cada intervalo de tempo de batelada, procede-se à união destes sub-DFA's gerados em um único diagrama, permitindo visualizar e auxiliar a montagem da configuração alternativa gerada, conforme mostra a Figura 3. O reúso da operação 2 nas operações 3 e 4 é simbolizado por um triângulo e um círculo, respectivamente, indicando a ordem na qual se estabeleceu a sequência do reúso.

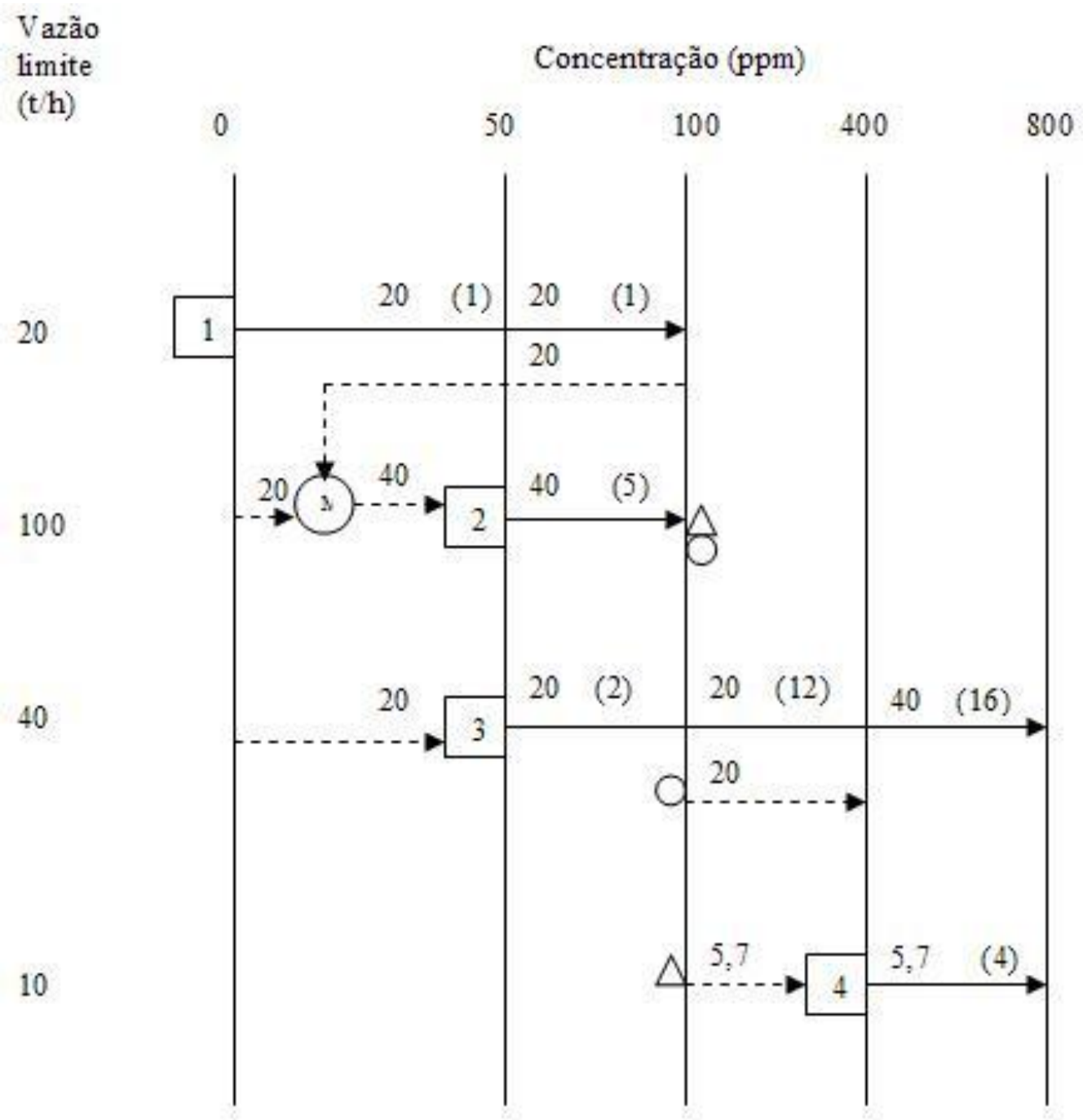

Figura 3. Esquema final da aplicação do método DFA.

A partir da estrutura unificada do DFA, torna-se possível construir um fluxograma representativo do processo hídrico, incluindo a configuração alternativa de reúso sugerida pela metodologia, conforme apresentado na Figura 4. 
MIRRE, R. C.; FERREIRA, S. C. L.; DIAS, A. R.; PESSOA, F. L. P. Conservação e reúso de águas usando o método Diagrama de Fontes de Água para processos em batelada: estudo de casos. Ambi-Agua, Taubaté, v.7, n. 1, p. 182-203, 2012. (http://dx.doi.org/10.4136/ambi-agua.565)

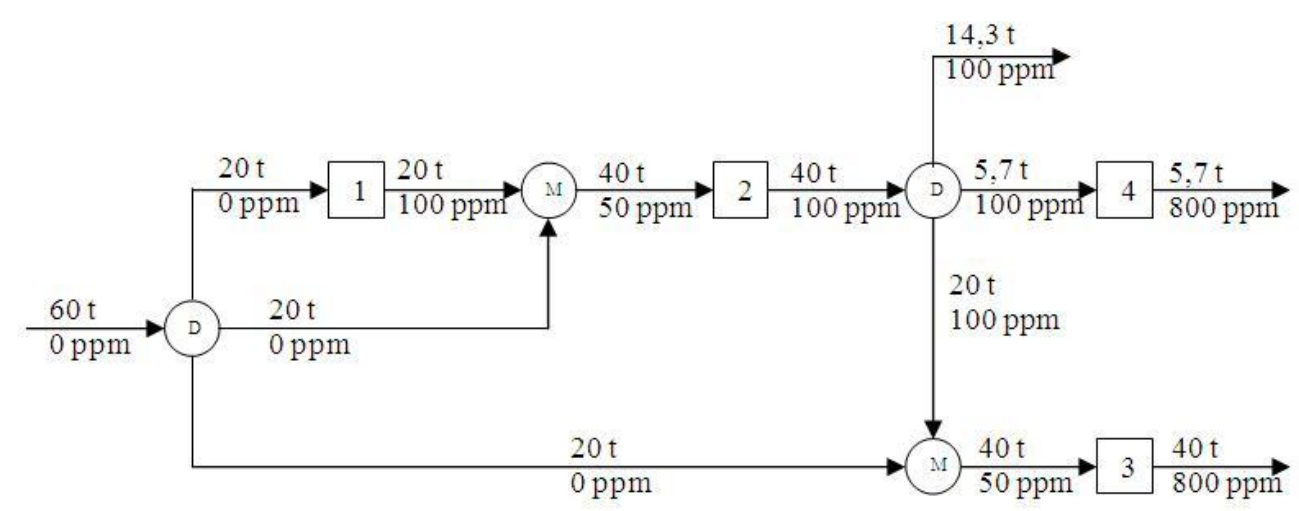

Figura 4. Fluxograma do processo hídrico.

A quantidade de água limpa utilizada no problema após a aplicação do DFA foi de 60 t, enquanto que a técnica empregada no trabalho de Foo et al. (2005b) utiliza uma quantidade de 211,25 t de água limpa, o que equivale a uma redução superior a $71 \%$.

Vale observar, entretanto, que o cenário estudado não inclui a existência de um tanque de estocagem, o que facilitaria a distribuição em qualquer intervalo subsequente para as operações dentro de um limite de armazenamento, além de não considerar a restrição de vazão fixa nas operações, permitindo obter valores menores de quantidade disponibilizada.

Um outro cenário pode ser analisado, em que se faz necessária a inclusão de um tanque de estocagem para a redestinação dos efluentes para as operações receptoras de reúso, desconsiderando a restrição de vazão fixa nas respectivas operações.

O procedimento adotado neste caso é similar ao anterior, em que se aplica o método DFA para cada intervalo de tempo. Ao final do primeiro intervalo de tempo de batelada $(0-1,0 \mathrm{~h})$, a operação 1 torna-se finalizada, tendo disponíveis 20 t para eventual reúso. Esta quantidade pode ser então armazenada em um tanque de estocagem (simbolizado pelo círculo contendo pela letra E), com uma capacidade predeterminada (aqui não tratado) para redestinação a outras operações.

No segundo intervalo $(1,0-3,0 \mathrm{~h})$, a quantidade de água necessária para suprir a necessidade da operação 2 pode ser proveniente da operação 1 que, no período considerado, já se encontra finalizada e disponível para reúso. Trata-se da mesma situação anterior, em que se deve calcular, por meio de um balanço material no ponto de mistura, a quantidade necessária de água que apresente a menor contribuição da água limpa $(0 \mathrm{ppm})$. Por ser o mesmo problema já abordado, a quantidade encontrada foi de 20 t de contribuição de água limpa e de $20 \mathrm{t}$ de água reutilizada do tanque de estocagem.

Similarmente ao primeiro cenário, o efluente da operação 2 pode ser prontamente reutilizado na operação 4, onde são necessários 5,7 t para assimilar a carga desta operação dentro do intervalo de $100 \mathrm{ppm}$ (de onde se busca o efluente para reúso) a $800 \mathrm{ppm}$.

No terceiro intervalo $(3,0-3,5 \mathrm{~h})$, a parcela remanescente da operação 2 , não reutilizada na operação 4, é agora destinada na quantidade de 20 t na operação 3, no intervalo entre 100 ppm e 400 ppm.

No quarto e último intervalo $(3,5-5,0 \mathrm{~h})$, está presente apenas a operação 3 e a quantidade necessária para assimilação do contaminante já se torna suficiente.

Como no primeiro cenário, procede-se à união dos sub-DFA's, de acordo com o diagrama da Figura 5. O reúso da operação 2 nas operações 3 e 4 é simbolizado por um triângulo e um círculo, respectivamente, indicando a ordem na qual se estabeleceu a sequência de reúso. O círculo maior que envolve as figuras geométricas menores ao término da operação 2 indica a existência de um tanque de estocagem; entretanto, o fato de se utilizar água limpa para diluir a concentração de entrada na operação 1 a 50 ppm dificulta a localização de um 
MIRRE, R. C.; FERREIRA, S. C. L.; DIAS, A. R.; PESSOA, F. L. P. Conservação e reúso de águas usando o método Diagrama de Fontes de Água para processos em batelada: estudo de casos. Ambi-Agua, Taubaté, v.7, n. 1, p. 182-203, 2012. (http://dx.doi.org/10.4136/ambi-agua.565)

único tanque para receber as correntes de ambos, o que poderia ser sugerido caso todas estivessem na mesma concentração de entrada do tanque (100 ppm), sem influenciar a qualidade do reúso.

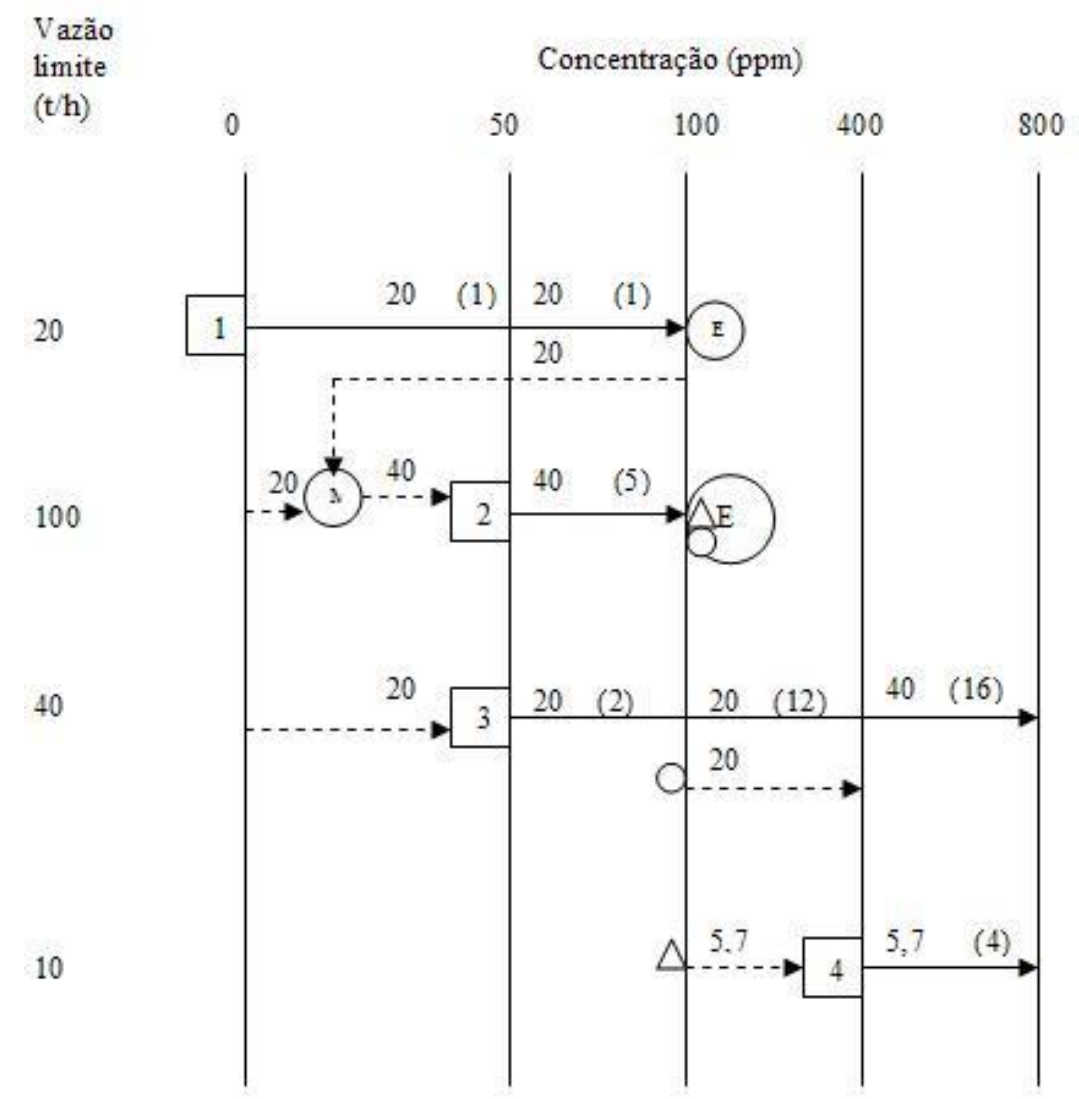

Figura 5. Esquema final do DFA para o novo cenário.

A partir da estrutura unificada do DFA, torna-se possível construir um fluxograma representativo do processo hídrico, incluindo a configuração alternativa de reúso sugerida pela metodologia, conforme apresentado na Figura 6.

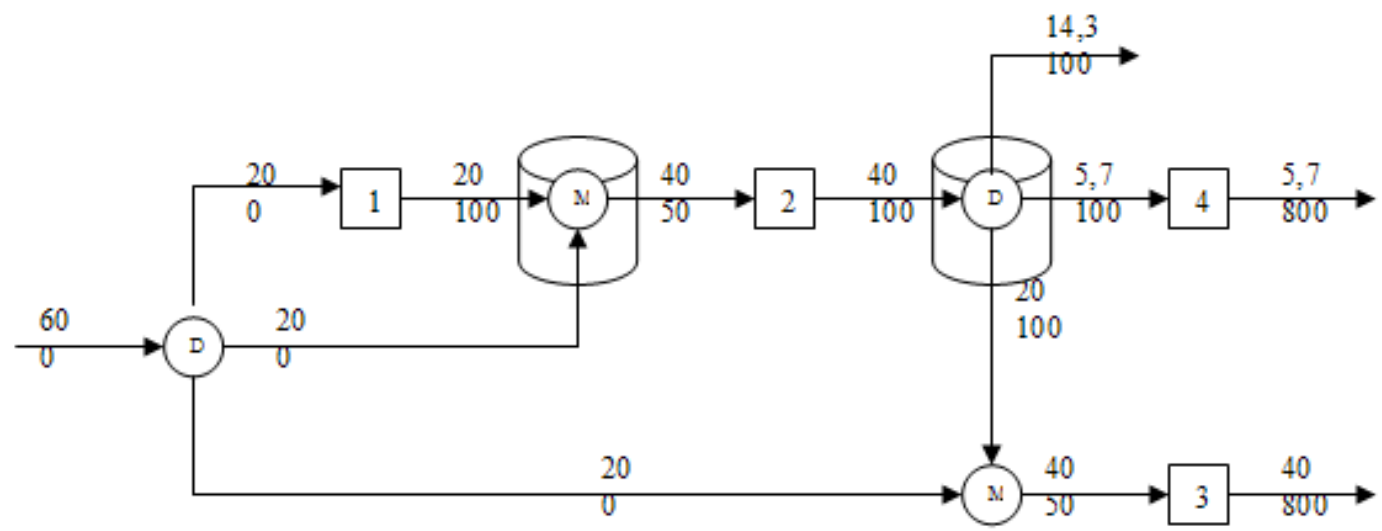

Figura 6. Fluxograma do processo hídrico para o novo cenário considerando a presença de tanque de estocagem. 
MIRRE, R. C.; FERREIRA, S. C. L.; DIAS, A. R.; PESSOA, F. L. P. Conservação e reúso de águas usando o método Diagrama de Fontes de Água para processos em batelada: estudo de casos. Ambi-Agua, Taubaté, v.7, n. 1, p. 182-203, 2012. (http://dx.doi.org/10.4136/ambi-agua.565)

Este exemplo ilustrou a necessidade de se estocar apenas a quantidade de água necessária para reúso. Esta quantidade armazenada no tanque servirá como fonte para as operações dos intervalos posteriores de tempo, de acordo com a lógica estabelecida para o primeiro cenário. Com o tanque de estocagem, a operação 1 pode enviar o efluente tanto para a operação 2 como para as operações 3 e 4. Diante de tal situação, optou-se por destiná-la integralmente para a operação 2, combinando-o à parcela de água limpa, permitindo a comparação com os resultados do primeiro cenário.

Neste trabalho, a metodologia apresentada para aplicação do método DFA a processos em batelada foi adotada para a realização de dois estudos de caso, de modo a auxiliar na minimização do consumo de água limpa. Foram apresentados dois casos existentes na literatura, em que o DFA é tratado como uma opção de técnica sistemática voltada para o reúso, avaliando oportunidades de nova configuração para o processo e de diminuição da quantidade de água limpa requerida para cada batelada. Assim, a Figura 7 sintetiza os cenários utilizados neste trabalho, tornando clara a divisão entre os casos.

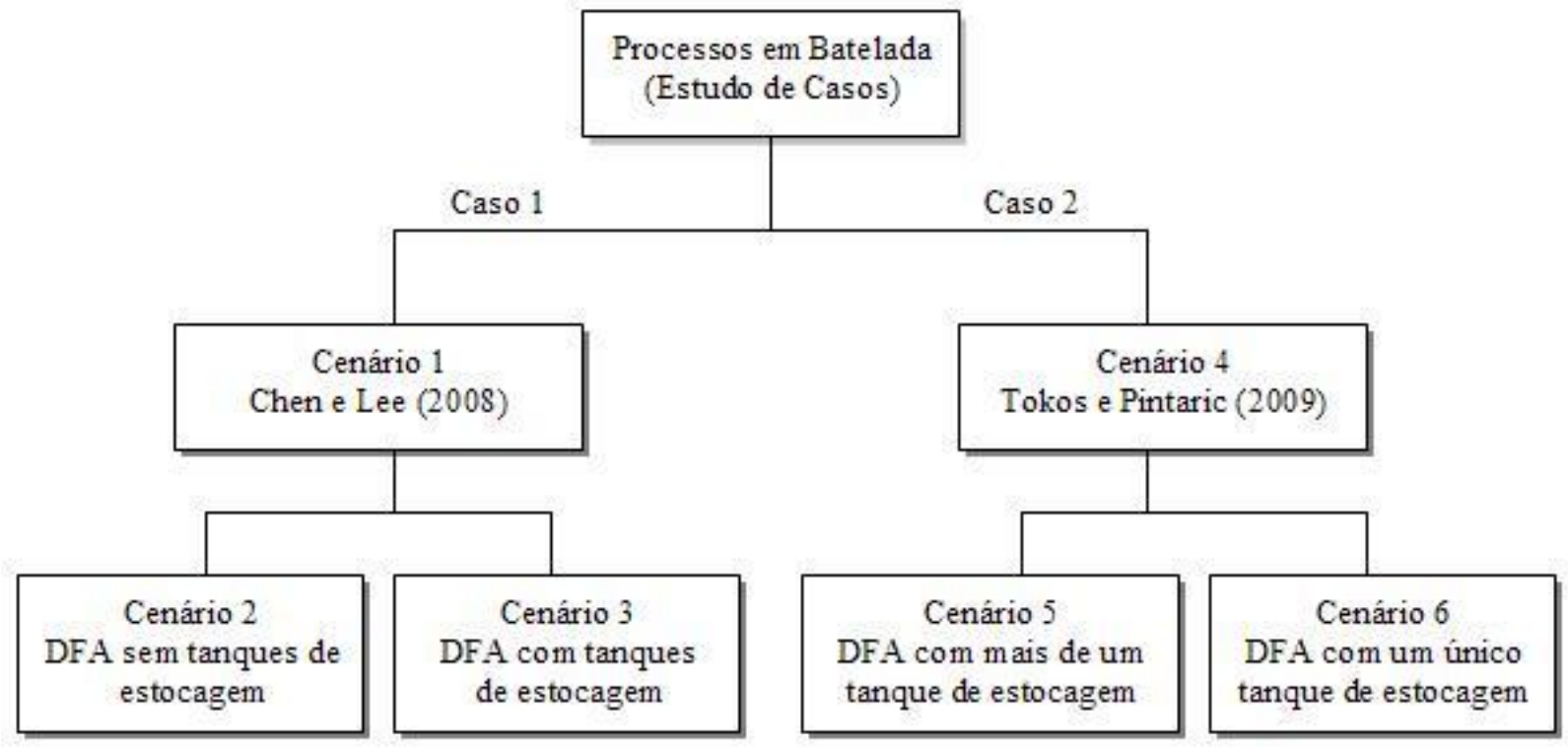

Figura 7. Estruturação dos cenários apresentados.

\subsection{Caso 1: apresentação do cenário 1}

O primeiro caso estudado refere-se a uma unidade hipotética apresentada por Chen e Lee (2008), na qual possui cinco operações que utilizam água e operam em regime de batelada. Para cada operação, têm-se as concentrações máximas de entrada (Ce,max) e saída (Cs,max) e a massa trocada de contaminante $(\Delta \mathrm{m})$. São também apresentados os intervalos de tempo de input (abastecimento) e output (descarregamento). Esses dados encontram-se relacionados na Tabela 3.

Tabela 3. Dados para a unidade hipotética (Chen e Lee, 2008).

\begin{tabular}{c|ccccc}
\hline Operação & $\begin{array}{c}\text { Intervalo de } \\
\text { input }(\mathbf{h})\end{array}$ & $\begin{array}{c}\text { Intervalo de } \\
\text { output }(\mathbf{h})\end{array}$ & $\begin{array}{c}\text { Ce,max (kg } \\
\text { sal / kg água) }\end{array}$ & $\begin{array}{c}\text { Cs,max (kg } \\
\text { sal / kg água) }\end{array}$ & $\Delta \mathbf{m}(\mathbf{t})$ \\
\hline 1 & $0-1,0$ & $4,0-5,0$ & 0 & 0,20 & 4 \\
2 & $0-0,5$ & $4,5-5,0$ & 0,25 & 0,50 & 4 \\
3 & $5,06,5$ & $5,0-6,5$ & 0,10 & - & 0 \\
4 & $2,02,5$ & $6,5-7,0$ & 0,25 & 0,40 & 3,6 \\
5 & $7,08,5$ & $7,0-8,5$ & 0,10 & - & 0,3 \\
\hline
\end{tabular}


MIRRE, R. C.; FERREIRA, S. C. L.; DIAS, A. R.; PESSOA, F. L. P. Conservação e reúso de águas usando o método Diagrama de Fontes de Água para processos em batelada: estudo de casos. Ambi-Agua, Taubaté, v.7, n. 1, p. 182-203, 2012. (http://dx.doi.org/10.4136/ambi-agua.565)

Nas operações 3 e 5, as massas de contaminantes trocadas são desprezíveis, e possuem uma quantidade mínima requerida de $15 \mathrm{t}$, para cada uma delas.

Para este caso são consideradas bateladas não-cíclicas sem reciclo, ou seja, a água que sai ao final de uma operação não pode ser retornada para o início da mesma operação e, se um tanque de estocagem for utilizado, a água que sai do tanque de estocagem não pode retornar para o mesmo tanque. No estudo de Chen e Lee (2008), o consumo de água limpa para bateladas não-cíclicas sem reciclo foi de $44,50 \mathrm{t}$, para cada batelada.

A aplicação do método DFA para este caso requer a determinação da quantidade de água necessária, expressa em toneladas, ao invés de vazão limite de cada operação. Assim, como a massa de contaminante trocada é desprezível para as operações 3 e 5, não são informadas as concentrações de saída para estas operações. Na implementação do DFA, a quantidade de água necessária é tratada como vazão para estas operações: 15 t cada uma delas.

Para as operações 1, 2 e 4, calcula-se a quantidade de água necessária para cada operação, de acordo com a Equação 1.

$$
\mathrm{f}_{\mathrm{k}}=\Delta \mathrm{m}_{\mathrm{i}} /\left(\mathrm{C}_{\mathrm{s}, \mathrm{i}}-\mathrm{C}_{\mathrm{e}, \mathrm{i}}\right)
$$

em que $f_{k}$ representa a quantidade de água para cada operação.

A Tabela 4 apresenta os valores calculados para as respectivas operações.

Tabela 4. Dados de concentração e quantidade de água para cada operação.

\begin{tabular}{c|cccccc}
\hline Operação & $\begin{array}{c}\text { Intervalo de } \\
\text { input (h) }\end{array}$ & $\begin{array}{c}\text { Intervalo de } \\
\text { output (h) }\end{array}$ & $\begin{array}{c}\text { Ce,max (kg sal } \\
\text { / kg água) }\end{array}$ & $\begin{array}{c}\text { Cs,max (kg sal } \\
\text { / kg água) }\end{array}$ & $\Delta \mathbf{m}(\mathbf{t})$ & $\mathbf{f}_{\mathbf{k}}(\mathbf{t})$ \\
\hline 1 & $0-1,0$ & $4,0-5,0$ & 0 & 0,20 & 4 & 20 \\
2 & $0-0,5$ & $4,5-5,0$ & 0,25 & 0,50 & 4 & 16 \\
3 & $5,0-6,5$ & $5,0-6,5$ & 0,10 & - & 0 & 15 \\
4 & $2,0-2,5$ & $6,5-7,0$ & 0,25 & 0,40 & 3,6 & 24 \\
5 & $7,0-8,5$ & $7,0-8,5$ & 0,10 & - & 0,3 & 15 \\
\hline
\end{tabular}

Em um sistema não-contínuo, a aplicação do DFA leva em conta os intervalos de tempo em que as operações são iniciadas e finalizadas, a fim de analisar a possibilidade de reúso. Neste caso, a corrente de saída de uma operação só pode ser reutilizada em outra se a primeira operação já estiver finalizada.

Outro fator a ser considerado refere-se à possibilidade de se manter tanques de estocagem. A ausência de tanques de estocagem implica o descarte de efluente ao final do processo. Assim, se não houver um tanque onde a água que sai do processo possa ser estocada, o efluente de uma operação só pode ser reutilizado em outra caso a primeira finalize exatamente no momento em que a outra se inicia. Na presença de um ou mais tanques de estocagem no processo, o efluente de uma operação pode ser estocado no momento em que a operação termina e, como a água pode ser armazenada, esta pode ser reutilizada em um processo que se inicie horas depois.

Duas oportunidades foram avaliadas neste estudo de caso: (i) ausência de tanques de estocagem, e (ii) considerando o uso de tanques de estocagem. 
MIRRE, R. C.; FERREIRA, S. C. L.; DIAS, A. R.; PESSOA, F. L. P. Conservação e reúso de águas usando o método Diagrama de Fontes de Água para processos em batelada: estudo de casos. Ambi-Agua, Taubaté, v.7, n. 1, p. 182-203, 2012. (http://dx.doi.org/10.4136/ambi-agua.565)

\subsection{Caso 2: apresentação do cenário 4}

O segundo caso aqui estudado é tratado por Tokos e Pintarič (2009), que propuseram uma estratégia de reúso utilizando um modelo matemático desenvolvido por Kim e Smith (2004), para diversos setores de uma cervejaria. Neste estudo, considerou-se apenas o setor de produção, que possui operações em regime de batelada. Este setor é constituído por seis processos não-contínuos e que consomem no total 1.076 t de água limpa por dia. Os dados limites de cada operação, divididos em intervalos de tempo, são apresentados na Tabela 5.

Tabela 5. Dados limite para as operações da unidade de produção (Tokos e Pintarič, 2009).

\begin{tabular}{|c|c|c|c|c|c|}
\hline \multirow{2}{*}{ Processo } & \multirow{2}{*}{$\begin{array}{l}\text { Tempo de } \\
\text { intervalo }\end{array}$} & \multicolumn{2}{|c|}{ Concentração limite (ppm) } & \multirow{2}{*}{$\mathbf{f}_{\mathbf{k}}(\mathbf{t})$} & \multirow{2}{*}{$\begin{array}{c}\text { Tempo de } \\
\text { operação (h) }\end{array}$} \\
\hline & & Ce,max & Cs, max & & \\
\hline \multirow{4}{*}{1} & $1(\mathrm{P} 1)$ & 24,25 & 425 & 41 & 4 \\
\hline & $2(\mathrm{P} 2)$ & 24,25 & 425 & 41 & 4 \\
\hline & $3(\mathrm{P} 3)$ & 24,25 & 425 & 41 & 4 \\
\hline & $4(\mathrm{P} 4)$ & 24,25 & 425 & 41 & 4 \\
\hline \multirow[t]{2}{*}{2} & $4(\mathrm{P} 5)$ & 100 & 299 & 261 & 4 \\
\hline & $1(\mathrm{P} 6)$ & 100 & 980 & 47,20 & 4 \\
\hline \multirow{3}{*}{3} & $2(\mathrm{P} 7)$ & 100 & 980 & 47,20 & 4 \\
\hline & $3(\mathrm{P} 8)$ & 100 & 980 & 47,20 & 4 \\
\hline & $4(\mathrm{P9})$ & 100 & 980 & 47,20 & 4 \\
\hline \multirow{4}{*}{4} & $1(\mathrm{P} 10)$ & 100 & 330 & 46,20 & 4 \\
\hline & $2(\mathrm{P} 11)$ & 100 & 330 & 46,20 & 4 \\
\hline & $3(\mathrm{P} 12)$ & 100 & 330 & 46,20 & 4 \\
\hline & $4(\mathrm{P} 13)$ & 100 & 330 & 46,20 & 4 \\
\hline \multirow{2}{*}{5} & 2 (P14) & 24,25 & 56 & 46,90 & 4 \\
\hline & $4(\mathrm{P} 15)$ & 24,25 & 56 & 46,90 & 4 \\
\hline 6 & $2(\mathrm{P} 16)$ & 100 & 329 & 115,30 & 4 \\
\hline
\end{tabular}

O processo 1 é uma unidade de fervura de mosto; os processos 2 e 5 são sistemas de limpeza; já nas operações 3 e 4 , a água é utilizada para verter materiais no processo de batelada; e a operação 6 é uma unidade de filtração.

\section{RESULTADOS E DISCUSSÃO}

\subsection{Caso 1: DFA sem o uso de tanques de estocagem - cenário 2}

Aplicando-se o método DFA aos dados do problema, tem-se o diagrama representado pela Figura 8. Os intervalos de concentrações foram definidos, e as operações foram dispostas no diagrama de acordo com as concentrações limites de entrada e saída para o contaminante em cada operação. 
MIRRE, R. C.; FERREIRA, S. C. L.; DIAS, A. R.; PESSOA, F. L. P. Conservação e reúso de águas usando o método Diagrama de Fontes de Água para processos em batelada: estudo de casos. Ambi-Agua, Taubaté, v.7, n. 1, p. 182-203, 2012. (http://dx.doi.org/10.4136/ambi-agua.565)

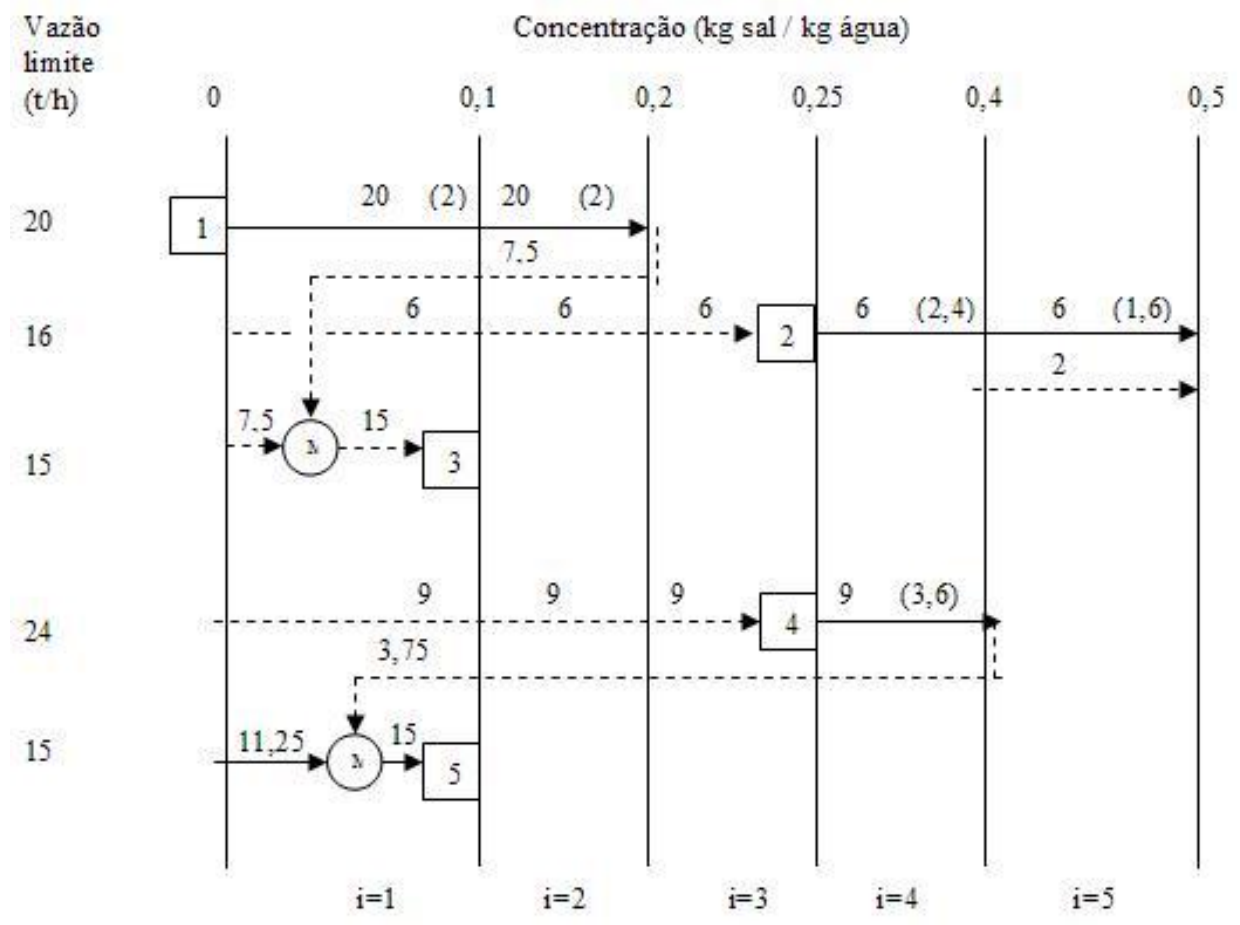

Figura 8. DFA gerado para caso 1 - sem tanques de estocagem.

Após esta etapa, o reúso foi avaliado de acordo com os intervalos de tempo das respectivas operações. O diagrama de blocos (fluxograma) do sistema está representado pela Figura 9.

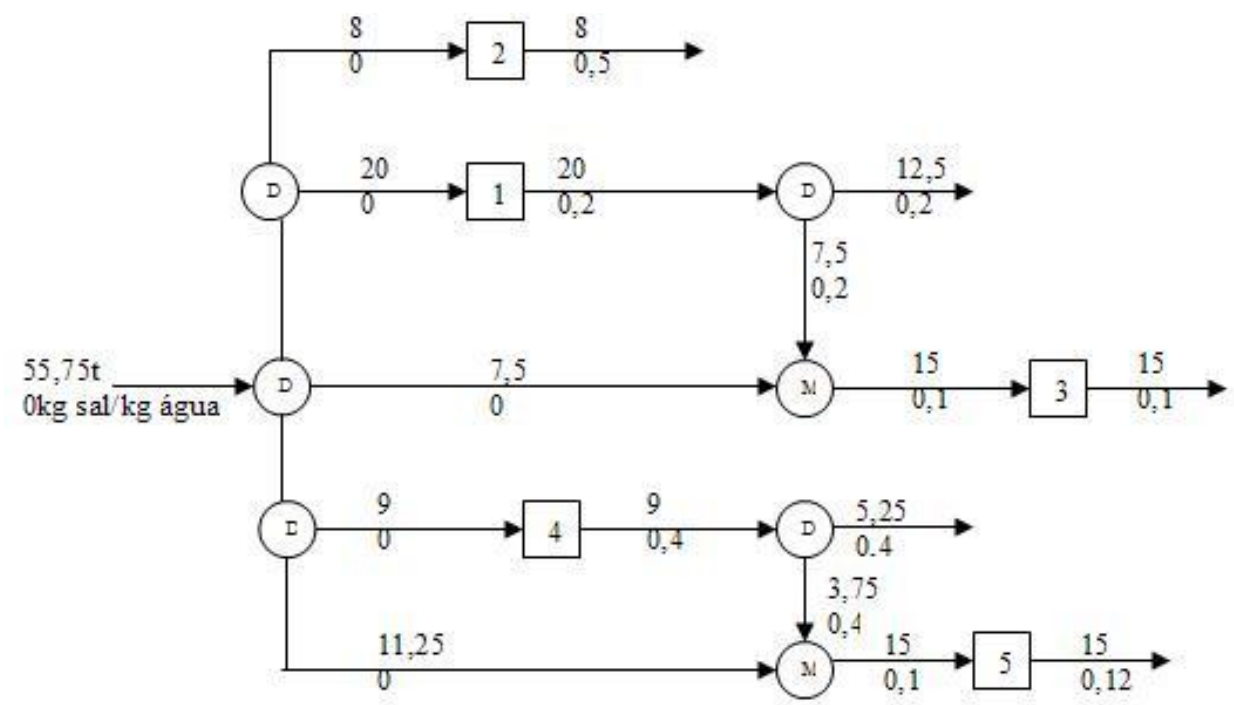

Figura 9. Fluxograma gerado - sem tanque de estocagem.

O consumo de água é de 55,75 t de água, superior ao do cenário 1, o que torna a proposta não recomendável para esta situação, sem o emprego de tanque de estocagem. 
MIRRE, R. C.; FERREIRA, S. C. L.; DIAS, A. R.; PESSOA, F. L. P. Conservação e reúso de águas usando o método Diagrama de Fontes de Água para processos em batelada: estudo de casos. Ambi-Agua, Taubaté, v.7, n. 1, p. 182-203, 2012. (http://dx.doi.org/10.4136/ambi-agua.565)

\subsection{Caso 1: DFA com o uso de tanques de estocagem - cenário 3}

Diante do alcance de uma configuração cujo consumo de água é maior que o problema inicial, considera-se neste caso a possibilidade de utilização de tanques de estocagem (T1). A aplicação do método resulta no diagrama da Figura 10.

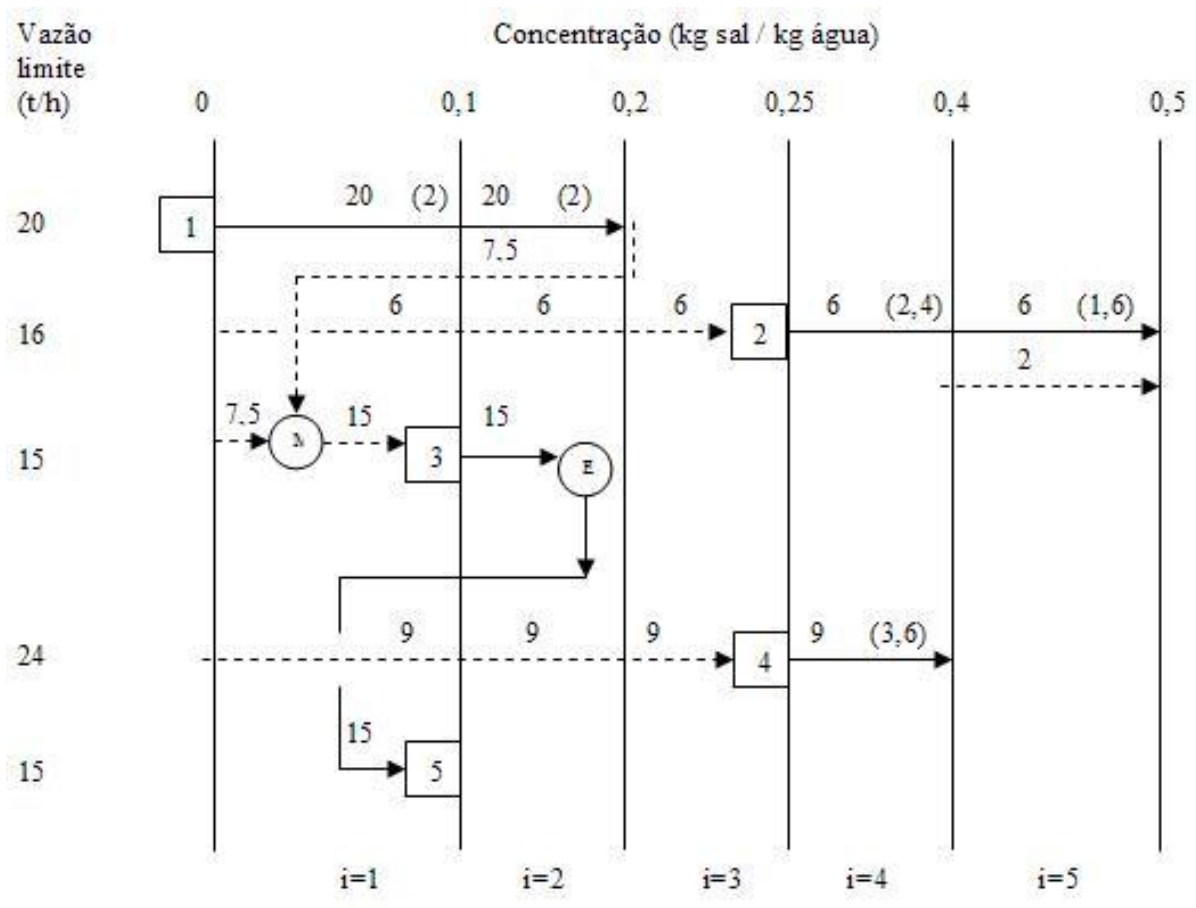

Figura 10. DFA gerado para o caso 1 - com uso de tanques de estocagem.

A Figura 11 apresenta uma proposta de fluxograma decorrente da aplicação do método. O consumo de água limpa é de 44,50 t por batelada, idêntico ao valor da proposta inicial apresentada por Chen e Lee (2008) (cenário 1).

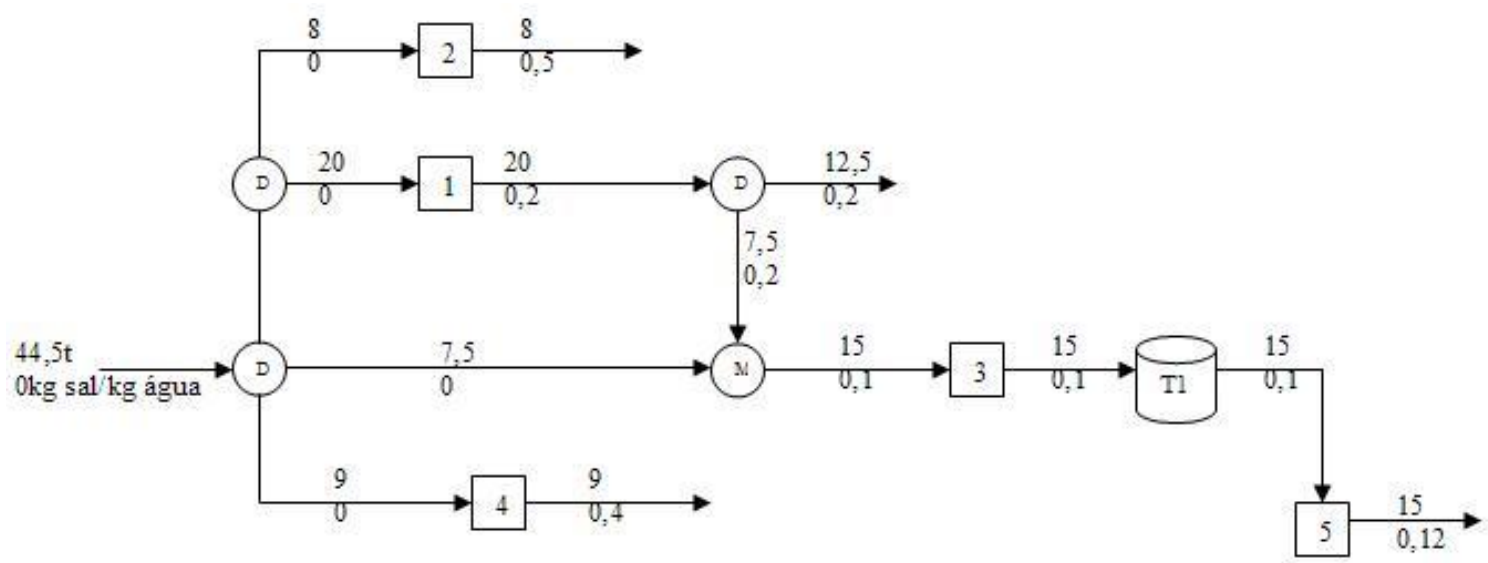

Figura 11. Fluxograma gerado - com tanque de estocagem (T1).

A metodologia aplicada em Tokos e Pintarič (2009) reduziu o consumo de água a 774,33 t/dia, gerando a mesma quantidade de efluente, destinado ao tratamento final de linha. Além disso, este procedimento requer o uso de unidades de tratamento da água. Foram regenerados neste processo 130,38 t de água, sendo necessário utilizar um tanque com capacidade para 
MIRRE, R. C.; FERREIRA, S. C. L.; DIAS, A. R.; PESSOA, F. L. P. Conservação e reúso de águas usando o método Diagrama de Fontes de Água para processos em batelada: estudo de casos. Ambi-Agua, Taubaté, v.7, n. 1, p. 182-203, 2012. (http://dx.doi.org/10.4136/ambi-agua.565)

43,46 t. Os dados limites para aplicação do método DFA encontram-se relacionados na Tabela 6.

Tabela 6. Dados limites do problema de Tokos e Pintarič (2009).

\begin{tabular}{c|cccc}
\hline Operação & Ce,max (ppm) & Cs, max (ppm) & $\mathbf{f}_{\mathbf{k}}(\mathbf{t})$ & Intervalo de tempo, ti (h) $-\mathbf{t f}(\mathbf{h})$ \\
\hline 1 & 24,25 & 425 & 41 & $0-16,0$ \\
2 & 100 & 299 & 261 & $12,0-16,0$ \\
3 & 100 & 980 & 47,20 & $0-16,0$ \\
4 & 100 & 330 & 46,20 & $0-16,0$ \\
5 & 24,25 & 56 & 46,90 & $4,0-8,0 \mathrm{e} 12,0-16,0$ \\
6 & 100 & 329 & 115,30 & $4,0-8,0$ \\
\hline
\end{tabular}

A operação 5 é uma operação de limpeza que ocorre em dois intervalos de tempo distintos. Por essa razão, visando à aplicação do método, a operação foi dividida em duas: (i) a operação 5', que ocorre no intervalo de 4 h a 8 h; e (ii) a operação 5', que ocorre no intervalo de $12 \mathrm{~h}$ a $16 \mathrm{~h}$. A Tabela 7 inclui os dados com essa adaptação.

Tabela 7. Dados adaptados para o cenário 4.

\begin{tabular}{c|cccc}
\hline Operação & Ce, $\mathbf{m a x}(\mathbf{p p m})$ & $\mathbf{C s ,} \mathbf{m a x}(\mathbf{p p m})$ & $\mathbf{f}_{\mathbf{k}}(\mathbf{t})$ & Intervalo de tempo, ti $(\mathbf{h})-\mathbf{t f}(\mathbf{h})$ \\
\hline 1 & 24,25 & 425 & 41 & $0-16,0$ \\
2 & 100 & 299 & 261 & $12,0-16,0$ \\
3 & 100 & 980 & 47,20 & $0-16,0$ \\
4 & 100 & 330 & 46,20 & $0-16,0$ \\
5, & 24,25 & 56 & 46,90 & $4,0-8,0$ \\
5, & 24,25 & 56 & 46,90 & $12,0-16,0$ \\
6 & 100 & 329 & 115,30 & $4,0-8,0$ \\
\hline
\end{tabular}

Neste problema, não existem operações que terminam no mesmo instante em que outras se iniciam, sendo necessário utilizar tanques de estocagem para que sejam levantadas oportunidades de reúso. Assim, avaliaram-se duas opções neste caso: na primeira, o método foi aplicado considerando a possibilidade de se utilizar mais de um tanque de estocagem; na segunda opção, utilizou-se somente um tanque de estocagem, recebendo as correntes de saída de todas as operações passíveis de reúso.

\subsection{Caso 2: DFA com mais de um tanque de estocagem - cenário 5}

O método foi aplicado considerando a possibilidade de se utilizar um tanque de estocagem para a saída de cada operação, de tal modo que pudesse ser reutilizada em outra que se inicie em um instante posterior. $O$ procedimento foi similar ao adotado no caso 1.

Para as operações $1,3,4,5$ ' e 6 , não existem outras fontes de água disponíveis, além da fonte externa. No momento em que estas operações se iniciam, nenhuma outra está finalizada, o que inviabiliza o reúso.

No instante $\mathrm{t}=12 \mathrm{~h}$ iniciam-se as operações 2 e 5". Como os intervalos de tempo são os mesmos, avalia-se primeiro a operação 5", pois seu início ocorre em um intervalo menor de concentração $(i=1)$.

Quando a operação 5" se inicia têm-se disponíveis duas fontes de água, provenientes das operações 5 ' e 6 , que terminaram em $t=8$ h. A saída de ambas viola a concentração 
MIRRE, R. C.; FERREIRA, S. C. L.; DIAS, A. R.; PESSOA, F. L. P. Conservação e reúso de águas usando o método Diagrama de Fontes de Água para processos em batelada: estudo de casos. Ambi-Agua, Taubaté, v.7, n. 1, p. 182-203, 2012. (http://dx.doi.org/10.4136/ambi-agua.565)

máxima de entrada da operação 5". Então, a operação selecionada para o reúso é a operação 5', já que possui menor concentração de saída que a operação 6 , e por isso menos água limpa terá que ser misturada a essa corrente, para que se alcance a concentração de entrada máxima na operação 5'. Assim, pode-se calcular a quantidade de água oriunda da operação 5', que requer a mínima quantidade de água limpa a ser misturada para o reúso, calculada em 26,59 t. O fluxograma obtido para este cenário encontra-se apresentado na Figura 12.

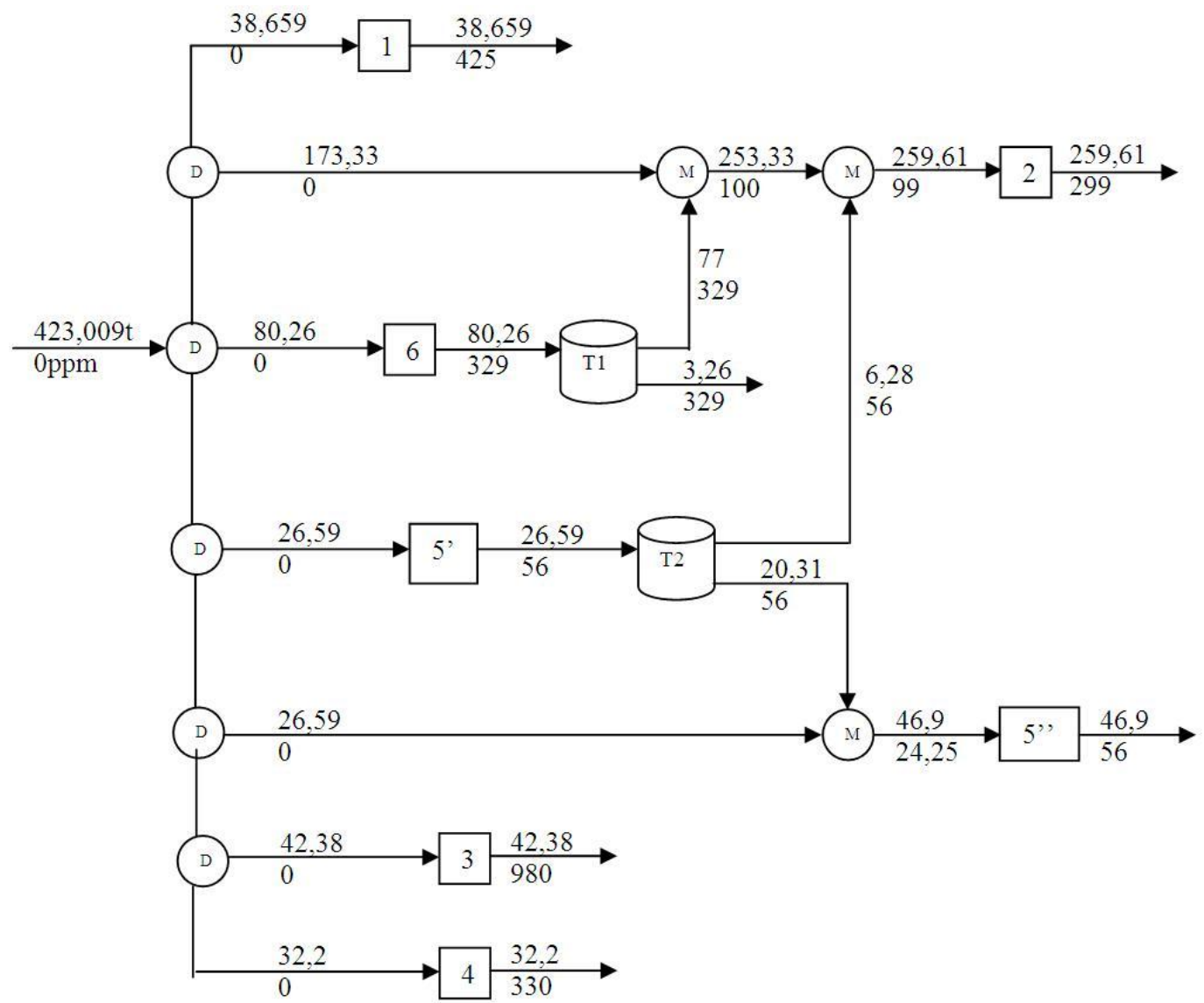

Figura 12. Fluxograma gerado - dois tanques de estocagem (T1 e T2).

Este cenário apresenta um consumo de água limpa de 423,01 t/dia. O consumo de água é $45,40 \%$ menor do que o consumo requerido para o cenário 4.

\subsection{Caso 2: DFA com apenas um tanque de estocagem - cenário 6}

Considerou-se aqui a possibilidade de se utilizar apenas um tanque de estocagem, para a aplicação do método.

Assim como no item anterior, as operações 1, 3, 4, 5' e 6 recebem água da fonte externa, e as saídas das operações 5' e 6 são reutilizadas nas operações 2 e 5'. No entanto, as saídas das operações 5' e 6 não são estocadas em diferentes tanques, sendo direcionadas para um mesmo tanque. Foram combinadas 26,59 t de água a 56 ppm com 80,26 t de água a 329 ppm, permitindo obter um tanque para recebimento de 106,85 t de água a $261 \mathrm{ppm}$. Com isso, a água estocada neste tanque em $\mathrm{t}=8 \mathrm{~h}$ é utilizada para alimentar as operações 2 e 5 ", que se iniciam em instantes posteriores; como a concentração de $261 \mathrm{ppm}$ é superior às concentrações limites de entrada de ambas operações, é necessário adicionar água limpa a estas correntes. 
MIRRE, R. C.; FERREIRA, S. C. L.; DIAS, A. R.; PESSOA, F. L. P. Conservação e reúso de águas usando o método Diagrama de Fontes de Água para processos em batelada: estudo de casos. Ambi-Agua, Taubaté, v.7, n. 1, p. 182-203, 2012. (http://dx.doi.org/10.4136/ambi-agua.565)

As quantidades de água limpa e de água proveniente do tanque a serem utilizadas para o reúso foram determinadas por meio de balanço material, como nos casos anteriores, e suas quantidades são descritas no fluxograma da Figura 13.

A demanda de água para este cenário foi de 423,63 t, representando uma redução de 45,20\% em relação à proposta inicial (cenário 4). Foram geradas 423,63 t de efluentes a serem destinados ao tratamento final.

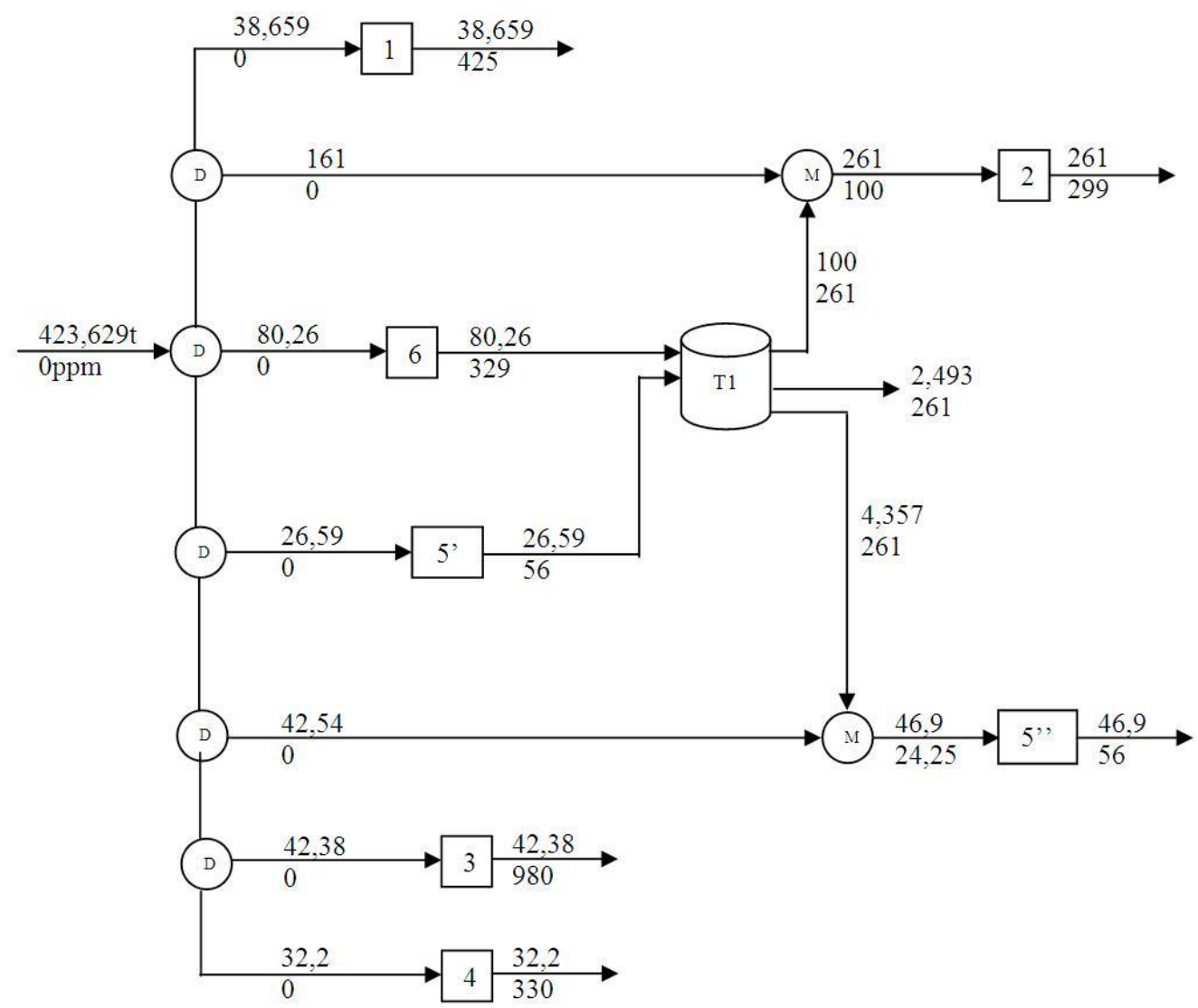

Figura 13. Fluxograma gerado - um tanque de estocagem (T1).

\subsection{Análise preliminar de custos}

As propostas de cenários promissores devem ser analisadas quanto à viabilidade econômica de sua implantação. Uma análise preliminar envolvendo a determinação de custos de investimento, que incorpora a parcela fixa, o capital de giro e a partida da planta, foi realizada.

As correlações para o cálculo dos custos de investimento e operacional relativos ao tratamento final de linha (end-of-pipe) e ao processo regenerativo disponível (stripping), adotado para fins comparativos, foram obtidas do trabalho de Wang e Smith (1994a). A depreciação anual do custo de capital é de 0,1 .

Para o caso 1, considerou-se como custo de investimento o custo da unidade de tratamento final e o custo dos tanques $\left(\mathrm{C}_{\mathrm{t}}\right)$, quando existem. Neste trabalho, utilizou-se uma correlação (Equação 2) obtida a partir de dados de Tokos e Pintarič (2009), relacionando um tanque cuja capacidade é de 43,36 t ao custo de 4.036,00 $€$, ou cerca de US\$ 5.560,00 (considerando $1,00 €=>$ US\$ 1,377), supondo que o tanque seja fabricado em aço inoxidável. A expressão torna-se válida para valores de capacidade de mesma ordem de grandeza.

$$
\mathrm{C}_{\mathrm{t}}=397,3 \cdot \mathrm{Q}^{0,7}
$$

em que Q é a capacidade de estocagem de água do tanque, em toneladas. 
MIRRE, R. C.; FERREIRA, S. C. L.; DIAS, A. R.; PESSOA, F. L. P. Conservação e reúso de águas usando o método Diagrama de Fontes de Água para processos em batelada: estudo de casos. Ambi-Agua, Taubaté, v.7, n. 1, p. 182-203, 2012. (http://dx.doi.org/10.4136/ambi-agua.565)

Assim, para um tanque com capacidade de $15 \mathrm{t}$, o investimento estimado foi da ordem de US\$2.673,00. Como cada batelada dura 8,5 h, admite-se que a unidade realize duas bateladas por dia, a fim de se estimar o custo anual.

Os resultados relativos a cada cenário obtido, em termos de vazão de água captada, efluente e água regenerada, encontram-se sintetizados na Tabela 8; já a Tabela 9 apresenta os custos estimados para cada cenário. Considera-se que o sistema opere 310 dias por ano, ou $5.270 \mathrm{~h} / \mathrm{ano}$, e que o custo da água tratada (0 ppm) seja de $0,3 \mathrm{US} \$ / \mathrm{t}$.

Tabela 8. Vazão de água captada, efluente e água regenerada para os cenários estudados.

\begin{tabular}{|c|c|c|c|c|}
\hline \multicolumn{5}{|c|}{ Caso 1} \\
\hline Cenário & $\begin{array}{l}\text { Consumo de } \\
\text { água por } \\
\text { batelada (t) }\end{array}$ & $\begin{array}{l}\text { Efluente para } \\
\text { tratamento } \\
\text { final (t) }\end{array}$ & $\begin{array}{c}\text { Água } \\
\text { regenerada (t) }\end{array}$ & $\begin{array}{l}\text { Tanques de } \\
\text { estocagem }\end{array}$ \\
\hline 1 & 44,50 & 44,50 & - & $\begin{array}{c}01 \text { tanque: capacidade } \\
\text { de } 15 \mathrm{t}\end{array}$ \\
\hline 2 & 55,75 & 55,75 & - & - \\
\hline 3 & 44,50 & 44,50 & - & $\begin{array}{c}01 \text { tanque: capacidade } \\
\text { de } 15 \mathrm{t}\end{array}$ \\
\hline \multicolumn{5}{|c|}{ Caso 2} \\
\hline Cenário & $\begin{array}{l}\text { Consumo de } \\
\text { água por } \\
\text { batelada (t) }\end{array}$ & $\begin{array}{l}\text { Efluente para } \\
\text { tratamento } \\
\text { final (t) }\end{array}$ & $\begin{array}{c}\text { Água } \\
\text { regenerada (t) }\end{array}$ & $\begin{array}{l}\text { Tanques de } \\
\text { estocagem }\end{array}$ \\
\hline 4 & 774,33 & 774,33 & 180,38 & $\begin{array}{c}03 \text { tanques: capacidades } \\
\text { de } 43,36 \mathrm{t} \text { cada }\end{array}$ \\
\hline 5 & 423,01 & 423,01 & - & $\begin{array}{l}02 \text { tanques: capacidades } \\
\text { de } 80,26 \text { t e } 26,59 \mathrm{t}\end{array}$ \\
\hline 6 & 423,63 & 423,63 & - & $\begin{array}{c}01 \text { tanque: capacidade de } \\
106,85 \mathrm{t}\end{array}$ \\
\hline
\end{tabular}

Tabela 9. Custos estimados para os cenários estudados.

\begin{tabular}{|c|c|c|c|c|}
\hline \multicolumn{5}{|c|}{ Caso 1} \\
\hline Cenário & $\begin{array}{l}\text { Custo de } \\
\text { água limpa } \\
\text { (US\$/a) }\end{array}$ & $\begin{array}{c}\text { Custo de } \\
\text { tratamento final } \\
\text { do efluente (US\$/a) }\end{array}$ & $\begin{array}{c}\text { Custo de } \\
\text { investimento em } \\
\text { regeneração } \\
\text { (US\$/a) } \\
\end{array}$ & $\begin{array}{c}\text { Custo de } \\
\text { investimento em } \\
\text { tanques (US\$/a) }\end{array}$ \\
\hline 1 & $8.277,00$ & $76.514,02$ & - & $2.644,74$ \\
\hline 2 & $10.369,50$ & $91.865,22$ & - & - \\
\hline 3 & $8.277,00$ & $76.514,02$ & - & $2.644,74$ \\
\hline \multicolumn{5}{|c|}{ Caso 2} \\
\hline Cenário & $\begin{array}{l}\text { Custo de } \\
\text { água limpa } \\
\text { (US\$/a) }\end{array}$ & $\begin{array}{c}\text { Custo de } \\
\text { tratamento final } \\
\text { do efluente (US\$/a) }\end{array}$ & $\begin{array}{c}\text { Custo de } \\
\text { investimento em } \\
\text { regeneração } \\
\text { (US\$/a) } \\
\end{array}$ & $\begin{array}{c}\text { Custo de } \\
\text { investimento em } \\
\text { tanques (US\$/a) }\end{array}$ \\
\hline 4 & $144.025,38$ & $843.277,84$ & $175.609,23$ & $16.680,24$ \\
\hline 5 & $78.679,86$ & $499.784,16$ & - & $12.504,35$ \\
\hline 6 & $78.795,18$ & $500.412,97$ & - & $10.453,48$ \\
\hline
\end{tabular}


MIRRE, R. C.; FERREIRA, S. C. L.; DIAS, A. R.; PESSOA, F. L. P. Conservação e reúso de águas usando o método Diagrama de Fontes de Água para processos em batelada: estudo de casos. Ambi-Agua, Taubaté, v.7, n. 1, p. 182-203, 2012. (http://dx.doi.org/10.4136/ambi-agua.565)

Observa-se que a aplicação do método considerando o uso de tanque de estocagem constitui uma alternativa promissora, uma vez que o custo do caso base foi alcançado com o uso de metodologia mais simples do que a apresentada pela proposta inicial. Em relação ao caso 2, observa-se que a utilização do método levou a configurações de menores custos nesse processo, especialmente caso se adote um único tanque de estocagem para toda a unidade.

\section{CONCLUSÕES}

Este trabalho procurou contribuir para o desenvolvimento do método DFA, originalmente proposto para processos contínuos, para o caso de processos em batelada. $\mathrm{O}$ procedimento foi apresentado na forma de um exemplo da literatura, o que facilitou a discussão dos estudos de caso. Para cada intervalo de tempo de batelada foi aplicado um DFA, gerando sub-DFA's que se integram ao final, para que seja possível visualizar a elaboração do fluxograma hídrico. Dois estudos de caso foram realizados para estender a aplicação da metodologia. Os cenários gerados permitiram reduzir o consumo de água e a geração de efluentes em até $45 \%$, em relação à configuração inicial, com o uso de tanques de estocagem. Uma análise preliminar de custos também foi conduzida, em que o custo de investimento em tanques de estocagem reduziu em torno de $37 \%$, sem necessidade de processos regenerativos. Neste sentido, este trabalho procurou assinalar o potencial da metodologia aqui empregada, como uma alternativa flexível para o auxílio de ferramentas sistemáticas voltadas para a minimização do consumo de água e da geração de efluentes industriais, exercendo importante papel em um programa de gerenciamento de recursos hídricos.

\section{AGRADECIMENTOS}

Os autores agradecem ao Conselho Nacional de Desenvolvimento Científico e Tecnológico $(\mathrm{CNPq})$, pelo suporte financeiro.

\section{REFERÊNCIAS}

ALMATÓ, M.; ESPUÑA, A.; PUIGJANER, L. Optimisation of water use in batch process industries. Computers and Chemical Engineering, Oxford, v. 23, n. 10, p. 1427-1437, 1999. http://dx.doi.org/10.1016/S0098-1354(99)00302-6

ALMATÓ, M.; SANMARTÍ, E.; ESPUÑA, A.; PUIGJANER, L. Rationalizing the water use in the batch process industry. Computers and Chemical Engineering, Oxford, v. 21, Supplement, S971-S976, 1997.

ALVA-ARGÁEZ, A.; KOKOSSIS, A. C.; SMITH, R. Wastewater minimization of industrial systems using an integrated approach. Computers and Chemical Engineering, Oxford, v. 22, Supplement, S741-S744, 1998. http://dx.doi.org/10.1016/S00981354(98)00138-0

AMIM, R. S.; HASEGAWA, F. A.; LEITE, D. C.; PESSOA, F. L. P.; ULSON DE SOUZA, A. A. Aplicação do diagrama de fonte de água em processos em batelada - definição de metas. In: WORKSHOP GESTÃO E REÚSO DE ÁGUA NA INDÚSTRIA, 3., 22-24 nov. 2007, Florianópolis. Anais... Florianópolis: FEESC, 2007. 1 CD-ROM.

CASTRO, P.; MATOS, H.; FERNANDES, M. C.; PEDRO NUNES, C. Improvements for mass-exchange networks design. Chemical Engineering Science, Oxford, v. 54, n. 11, p. 1649-1665, 1999. http://dx.doi.org/10.1016/S0009-2509(98)00526-0 
MIRRE, R. C.; FERREIRA, S. C. L.; DIAS, A. R.; PESSOA, F. L. P. Conservação e reúso de águas usando o método Diagrama de Fontes de Água para processos em batelada: estudo de casos. Ambi-Agua, Taubaté, v.7, n. 1, p. 182-203, 2012. (http://dx.doi.org/10.4136/ambi-agua.565)

CHANG, C-T.; LI, B-H. Optimal design of wastewater equalization systems in batch processes. Computers and Chemical Engineering, Oxford, v. 30, n. 5, p.797-806, 2006. http://dx.doi.org/10.1016/j.compchemeng.2005.12.003

CHEN, C.; LEE, J. A graphical technique for the design of water-using networks in batch processes. Chemical Engineering Science, Oxford, v. 63, n. 14, p. 3740-3754, 2008. http://dx.doi.org/10.1016/j.ces.2008.04.047

CHEN, C-L.; LEE, J-Y.; TANG, J-W.; CIOU, Y-J. Synthesis of water-using network with central reusable storage in batch processes. Computers and Chemical Engineering, Oxford, v. 33, n. 1, p. 267-276, 2009.

http://dx.doi.org/10.1016/j.compchemeng.2008.09.013

DOYLE, S. J.; SMITH, R. Targeting water reuse with multiple contaminants. Process Safety and Environmental Protection, London, v. 75, n. 3, B, p. 181-189, 1997.

EL-HALWAGI, M. M.; MANOUSIOUTHAKIS, V. Synthesis of mass exchange networks. American Institute of Chemical Engineering Journal, New York, v. 35, n. 8, p. 1233-1244, 1989. http://dx.doi.org/10.1002/aic.690350802

FOO, C. Y.; MANAN, Z. A.; YUNUS, R. M.; AZIZ, R. A. Synthesis of mass exchange network for batch processes - Part I: utility targeting, Chemical Engineering Science, Oxford, v. 59, n. 5, p. 1009-1026, 2004. http://dx.doi.org/10.1016/j.ces.2003.09.043

FOO, C. Y.; MANAN, Z. A.; YUNUS, R. M.; AZIZ, R. A. Synthesis of mass exchange network for batch processes - Part II: minimum units target and batch network design, Chemical Engineering Science, Oxford, v. 60, n. 5, p. 1349-1362, 2005a. http://dx.doi.org/10.1016/j.ces.2004.10.008

FOO, D. C. Y.; MANAN, Z. A.; TAN, Y. L. Synthesis of maximum water recovery network for batch process systems, Journal of Cleaner Production, Knoxville, v. 13, n. 15, p. 1381-1394, 2005b. http://dx.doi.org/10.1016/j.jclepro.2005.04.013

GOMES, J. F. S.; QUEIROZ, E. M.; PESSOA, F. L. P. Design procedure for water/wastewater minimization: single contaminant. Journal of Cleaner Production, Knoxville, v. 15, n. 5, p. 474-485, 2007. http://dx.doi.org/10.1016/j.jclepro.2005.11.018

GOUWS, J. F.; MAJOZI, T. Usage of inherent storage for minimisation of wastewater in multipurpose batch plants. Chemical Engineering Science, Oxford, v. 64, n. 16, p. 3545-3554, 2009. http://dx.doi.org/10.1016/j.ces.2009.04.038

GOUWS, J. F.; MAJOZI, T.; GADALLA, M. Flexible mass transfer model for water minimization in batch plants. Chemical Engineering and Processing, New York, v. 47, n. 12, p. 2323-2335, 2008. http://dx.doi.org/10.1016/j.cep.2008.01.008

IMMICH, A. P. S.; GUSATTI, M.; MELLO, J. M. M.; GUELLI U.; SOUZA, S. M. A.; PESSOA, F. L. P. et al. Application of the water source diagram (WSD) procedure to water use minimization in a batch process. In: EUROPEAN CONGRESS OF CHEMICAL ENGINEERING, 6., 16-20 set. 2007, Copenhagen Proceedings... Copenhagen: EFCE, 2007. 1 CD-ROM.

JÖDICKE, G.; FISCHER, U.; HUNGERBÜHLER, K. Wastewater reuse: a new approach to screen for designs with minimal total costs. Computers and Chemical Engineering, Oxford, v. 25, n. 2/3, p. 203-215, 2001. 
MIRRE, R. C.; FERREIRA, S. C. L.; DIAS, A. R.; PESSOA, F. L. P. Conservação e reúso de águas usando o método Diagrama de Fontes de Água para processos em batelada: estudo de casos. Ambi-Agua, Taubaté, v.7, n. 1, p. 182-203, 2012. (http://dx.doi.org/10.4136/ambi-agua.565)

KIM, J. K.; SMITH, R. Automated design of discontinous water systems. Process Safety and Environmental Protection, London, v. 82, B3, p. 238-248, 2004. http://dx.doi.org/10.1205/095758204323066000

MAJOZI, T. Wastewater minimisation using central reusable water storage in batch plants. Computers and Chemical Engineering, Oxford, v. 29, n. 7, p. 1631-1646, 2005. http://dx.doi.org/10.1016/j.compchemeng.2005.01.003

MAJOZI, T.; BROUCKAERT, C. J.; BUCKLEY, C. A. A graphical technique for wastewater minimisation in batch processes. Journal of Environmental Management, New York, v. 78, n. 4, p. 317-329, 2006.

MAJOZI, T.; GOUWS, J. F. A mathematical optimisation approach for wastewater minimisation in multipurpose batch plants: multiple contaminants. Computers and Chemical Engineering, Oxford, v. 33, n. 11, p. 1826-1840, 2009a. http://dx.doi.org/10.1016/j.compchemeng.2009.06.008

MAJOZI, T.; GOUWS, J. F. Reliable method for water reuse in multicontaminant batch plants: NIS policy. Applied Mathematical Modelling, London, v. 33, n. 10, p. 37923800, 2009b. http://dx.doi.org/10.1016/j.apm.2008.12.005

MÉNDEZ, C. A.; CERDÁ, J.; GROSSMANN, I. E.; HARJUNKOSKI, I.; FAHL, M. Stateof-the-art review of optimization methods for short-term scheduling of batch processes. Computers and Chemical Engineering, Oxford, v. 30, n. 6/7, p. 913-946, 2006.

OLIVER, P.; RODRÍGUEZ, R.; UDAQUIOLA, S. Water use optimization in batch process industries. Part 1: design of the water network. Journal of Cleaner Production, Knoxville, v. 16, n. 12, p. 1275-1286, 2008. http://dx.doi.org/10.1016/j.jclepro.2007.06.012

PUIGJANER, L.; ESPUÑA, A.; ALMATÓ, M. A software tool for helping in decisionmaking about water management in batch process industries. Waste Management, New York, v. 20, n. 8, p. 645-649, 2000.

RABIE, A. H.; EL-HALWAGI, M. M. Synthesis and scheduling of optimal batch waterrecycle networks. Chinese Journal of Chemical Engineering, Beijing, v. 16, n. 3, p. 474-479, 2008.

SHOAIB, A. M.; ALY, S. M.; AWAD, M. E.; FOO, D. C. Y.; EL-HALWAGI, M. M. A hierarchical approach for the synthesis of batch water network. Computers and Chemical Engineering, Oxford, v. 32, n. 3, p. 530-539, 2008.

http://dx.doi.org/10.1016/j.compchemeng.2007.03.015

TOKOS, H.; PINTARIČ, Z. N. Synthesis of batch water network for a brewery plant. Journal of Cleaner Production, Knoxville, v. 17, n. 16, p. 1465-1479, 2009. http://dx.doi.org/10.1016/j.jclepro.2009.06.009

WANG, Y. P.; SMITH, R. Wastewater minimisation. Chemical Engineering Science, Oxford, v. 49, n. 7, p. 981-1006, 1994a. http://dx.doi.org/10.1016/0009-2509(94)80006-5

WANG, Y. P.; SMITH, R. Desing of distributed effluent treatment systems. Chemical Engineering Science, Oxford, v. 49, n. 18, p. 3127-3145, 1994b. http://dx.doi.org/10.1016/0009-2509(94)E0126-B 
MIRRE, R. C.; FERREIRA, S. C. L.; DIAS, A. R.; PESSOA, F. L. P. Conservação e reúso de águas usando o método Diagrama de Fontes de Água para processos em batelada: estudo de casos. Ambi-Agua, Taubaté, v.7, n. 1, p. 182-203, 2012. (http://dx.doi.org/10.4136/ambi-agua.565)

WANG, Y. P.; SMITH, R. Wastewater minimization with flowrate constraints. Transactions of the Institution of Chemical Engineers, London, v. 73 (A), p. 889-904, 1995a.

WANG, Y. P.; SMITH, R. Time pinch analysis. Transactions of the Institution of Chemical Engineers, London, v. 73 (A), p. 905-914, 1995 b.

ZHOU, R-J.; LI, L-J.; XIAO, W.; DONG, H-G. Simultaneous optimization of batch process schedules and water-allocation network. Computers and Chemical Engineering, Oxford, v. 33, n. 6, p. 1153-1168, 2009. http://dx.doi.org/10.1016/j.compchemeng.2008.11.008 